OPEN ACCESS

Edited by:

Alessandra Castegna,

University of Bari Aldo Moro, Italy

Reviewed by:

Cinzia Domenicotti,

University of Genoa, Italy

Daniel Pereira Bezerra,

Oswaldo Cruz Foundation

(Fiocruz), Brazil

*Correspondence:

Veronica Fiorito

veronica.fiorito@unito.it

Specialty section:

This article was submitted to

Cancer Metabolism,

a section of the journal

Frontiers in Oncology

Received: 27 October 2019 Accepted: 19 December 2019

Published: 15 January 2020

Citation:

Fiorito V, Chiabrando D, Petrillo $S$, Bertino F and Tolosano E (2020) The Multifaceted Role of Heme in Cancer.

Front. Oncol. 9:1540.

doi: 10.3389/fonc.2019.01540

\section{The Multifaceted Role of Heme in Cancer}

\author{
Veronica Fiorito*, Deborah Chiabrando, Sara Petrillo, Francesca Bertino and \\ Emanuela Tolosano
}

Department of Molecular Biotechnology and Health Sciences, Molecular Biotechnology Center, University of Torino, Turin, Italy

Heme, an iron-containing porphyrin, is of vital importance for cells due to its involvement in several biological processes, including oxygen transport, energy production and drug metabolism. Besides these vital functions, heme also bears toxic properties and, therefore, the amount of heme inside the cells must be tightly regulated. Similarly, heme intake from dietary sources is strictly controlled to meet body requirements. The multifaceted nature of heme renders it a best candidate molecule exploited/controlled by tumor cells in order to modulate their energetic metabolism, to interact with the microenvironment and to sustain proliferation and survival. The present review summarizes the literature on heme and cancer, emphasizing the importance to consider heme as a prominent player in different aspects of tumor onset and progression.

Keywords: heme, cancer, iron, metabolism, microenvironment (ME)

\section{INTRODUCTION}

The onset and progression of cancer rely on the ability of tumor cells to channel different biological processes toward the promotion of cell proliferation, the escape from immunosurveillance and the resistance to drugs. Inorganic iron has been reported to play pivotal roles in several aspects related to cancer metabolic adaptation and tumor microenvironment reprogramming (1-3). Similarly, organic iron, in the form of the iron-containing porphyrin heme, is potentially a best candidate molecule exploited/controlled by tumor cells in order to modulate the energetic metabolism, to interact with the microenvironment and to sustain proliferation and survival. Heme bears a series of functions that are far beyond those mediated by its iron atom, including oxygen transport and storage, drug and steroid metabolism, transcriptional and translational regulation, signal transduction and microRNA processing $(4,5)$. In addition, heme synthesis is a cataplerotic pathway for the tricarboxylic acid cycle, as it consumes succynil-CoA. However, among the different metabolic processes that cancer cells can regulate to meet their specific demands, heme metabolism has been so far marginally studied, and frequently the importance of heme for cancer has been attributed to the iron atom contained in heme, rather than to specific functions mediated by the entire heme molecule itself. The present review will summarize the literature on heme and cancer highlighting both positive and negative effects of heme on cancer cells and on components of the tumor microenvironment.

\section{DIETARY HEME AND CANCER}

Historically, the role of heme in cancer has been studied focusing on the effects mediated by exogenous dietary heme on the organism. These studies contributed to the current notion that 
dietary heme is a risk factor for cancer. Heme is an iron coordinating porphyrin contained predominantly in red and processed meat in the form of hemoglobin and myoglobin. Red meat refers to unprocessed mammalian muscle meat, while processed meat refers to meat that has been transformed through salting, curing, fermentation, smoking, or other processes to enhance flavor or improve preservation. Recently, the International Agency for Research on Cancer (IARC), following an assessment of over 800 studies performed world-wide, classified processed meat as group 1 "carcinogenic to humans" and fresh red meat as group 2A "probably carcinogenic to humans" (6). Conversely, no link between white meat and fish and cancer has been found (7-9). For this reason, heme has been proposed as the key molecule contributing to tumorigenesis upon red and processed meat intake.

The role of dietary heme in cancer has been highlighted in different types of carcinomas. Indeed, high consumption of red and processed meat has been associated with increased incidence of esophageal, gastric, breast, endometrial, pancreas and lung tumor (10-15), while no clear link was found for bladder and prostate cancer (16-18). However, the majority of studies focused on the role of dietary heme in the pathogenesis of colorectal cancer (CRC), still a leading cause of cancer deaths in Western Countries (19-21). Dietary heme is absorbed mostly in the upper part of the small intestine. Once absorbed, heme is degraded by the action of the enzymes heme oxygenases (HMOXs) into biliverdin, carbon monoxide $(\mathrm{CO})$, and iron $\left(\mathrm{Fe}^{2+}\right)$, that is then scavenged by the protein ferritin (4). However, if red/processed meat is assumed in large amounts, all the ingested heme cannot

\footnotetext{
Abbreviations: IARC, International Agency for Research on Cancer; CRC, colorectal cancer; HMOXs, heme oxygenases; CO, carbon monoxide; $\mathrm{Fe}^{2+}$, ferrous iron; ROS, reactive oxygen species; CHF, cytotoxic heme factor; LOOHs, lipid hydroxiperoxide; MDA, malondialdehyde; 4-HNE, 4-hydroxynonenal; APC, Adenomatous Polyposis Coli; NOC, N-nitroso compounds; ALA, 5aminolevulinic acid; ALAS1, 5-Amilolevulinate Synthase 1; ALAD, ALA dehydratase; PBGD, porphobilinogen deaminase; UROS, uroporphyrinogen III synthase; UROD, uroporphyrinogen decarboxylase; CPOX, coproporphyrinogen oxidase; PPOX, protoporphyrinogen oxidase; FECH, ferrochelatase; PpIX, protoporphyrin IX; FGS, tumor fluorescence-guided surgery; PDT, photodynamic therapy; ETC, electron transport chain; OXPHOS, oxidative phosphorylation; ATP, adenosine triphosphate; HLRCC, hereditary leiomyomatosis and renal-cell cancer; TCA cycle, tricarboxylic acid cycle; ATPIF1, ATPase Inhibitory Factor 1; $\mathrm{PDH}$, pyruvate dehydrogenase; ANT, adenine nucleotide transporter; GRBOX, glycolysis regulated box; TDO, tryptophan 2,3-dioxygenase; IDO1/2, indoleamine2,3-dioxygenase 1 and 2; CYP1B1, cytochrome P450 family 1 subfamily B member 1; COX2, prostaglandin-endoperoxide synthase 2; NSCLC, non-small cell lung cancer; NR1D1 or Rev-erb $\alpha$, nuclear receptor subfamily 1 group D member 1; NPAS2, neuronal PAS domain protein 2; PER2, period circadian regulator 2; HRM, heme-responsive motif; SLC46A1 or HCP1, solute carrier family 46 member 1; FLVCR2, feline leukemia virus subgroup C receptor family member 2; SLC48A1 or HRG1, solute carrier family 48 member 1; GLUT1, glucose transporter 1; FLVCR1, feline leukemia virus subgroup C receptor family member 1; ABCG2, ATP binding cassette subfamily G member 2; HER2, human epidermal growth factor receptor 2; TME, tumor microenvironment; TAMs, tumor-associated macrophages; RBCs, red blood cells; TECs, tumor-associated endothelial cells; ECM, extracellular matrix; MMPs, matrix metalloproteinases; CAFs, cancer-associated fibroblasts; MPO, myeloperoxidase; EPO, eosinophil peroxidase; NGF, nerve growth factor; DGCR8, DiGeorge critical region-8; miRNA, microRNA; CLOCK, clock circadian regulator; NCOR, nuclear receptor corepressor; HDAC3, histone deacetylase 3; GIS1, histone demethylase GIS1; jmjd-2/KDM4, lysine demethylase 4; AML, acute myeloid leukemia; CCs, cancer cells; Ac, acetylation; Me, methylation.
}

be absorbed by the small intestine and it accumulates for a considerable time in the large intestine $(22,23)$. In presence of high free heme levels both ferritin and HMOXs are saturated and cells accumulate free heme and labile iron that exert a variety of cytotoxic effects on intestinal mucosa (24). For example, heme is able to induce cytotoxic damage to surface epithelial cells that changes surface to crypt signaling, resulting in hyperproliferation and finally hyperplasia of crypt cells in heme-fed mice (25). Furthermore, free heme and labile iron accumulation result in the production of reactive oxygen species (ROS) that pathologically oxidize DNA, lipids and proteins. It has been well-demonstrated that ROS-induced DNA damage and gene mutations cause CRC and that proteins involved in CRC development are redox-sensitive (26). Additionally, ROS are able to induce lipid peroxidation of intestinal cells. Reactive lipid peroxides, formed by the action of ROS, covalently bind to the protoporphyrin ring of heme giving rise to an extremely lipophilic molecule, named cytotoxic heme factor (CHF) that induces cytotoxic damage on intestinal epithelial cells (27). To note, processed meat when in contact with gastric acid can also give rise to lipid hydroxiperoxide (LOOHs). $\mathrm{LOOH}$ is then broken down by the iron released by heme to produce free radicals and, subsequently, aldehyde molecules like malondialdehyde (MDA) and 4-hydroxynonenal (4-HNE) (28). MDA is toxic and it is able to bind DNA forming mutagenic adducts. 4-HNE induces apoptosis and kills normal cells, but not precancerous cells that are mutated on Adenomatous Polyposis Coli (APC) gene (29).

In addition to the processes described above, heme is also able to catalyze the formation of N-nitroso compounds (NOC) in the gastrointestinal tract (30). NOC are known carcinogens that can determine DNA mutation through alkylation, and high NOC concentrations have been associated to increased red meat consumption $(31,32)$. However, it is important to underline that NOC found after ingestion of red meat in humans consist mainly of nitrosyl iron and nitrosothiols, products that have profoundly different chemistries as compared to some tumorigenic $\mathrm{N}$-nitroso species (33). Therefore, more studies are required to clarify the real involvement of heme in NOC pro-tumor effects.

Finally, it has been demonstrated that heme alters the normal intestinal bacterial flora especially by decreasing the number of gram-positive bacteria (34) leading to a state of dysbiosis (microbial imbalance or maladaptation) that exacerbates colitis and adenoma formation in mice (35) and is correlated to the insurgence of CRC (35-37). Moreover, the gut microbiota can induce per se hyperproliferation via mechanisms occurring in the colon lumen, such as modulation of oxidative and cytotoxic stress or by influencing the mucus barrier, and these effects are intensified in presence of heme (38). Indeed, a recent study showed that mice receiving a diet with heme show an increased population of mucolytic bacteria in their colon. These bacteria, synergistically with heme-produced CHF, damage gut epithelium and lead to a compensatory aberrant hyperproliferation. Conversely, mice receiving heme together with antibiotics do not show this phenotype (38).

Overall, the studies on dietary heme and cancer support the idea that heme contained in food can sustain cancer by different mechanisms (Figure 1). However, it must be recognized that 


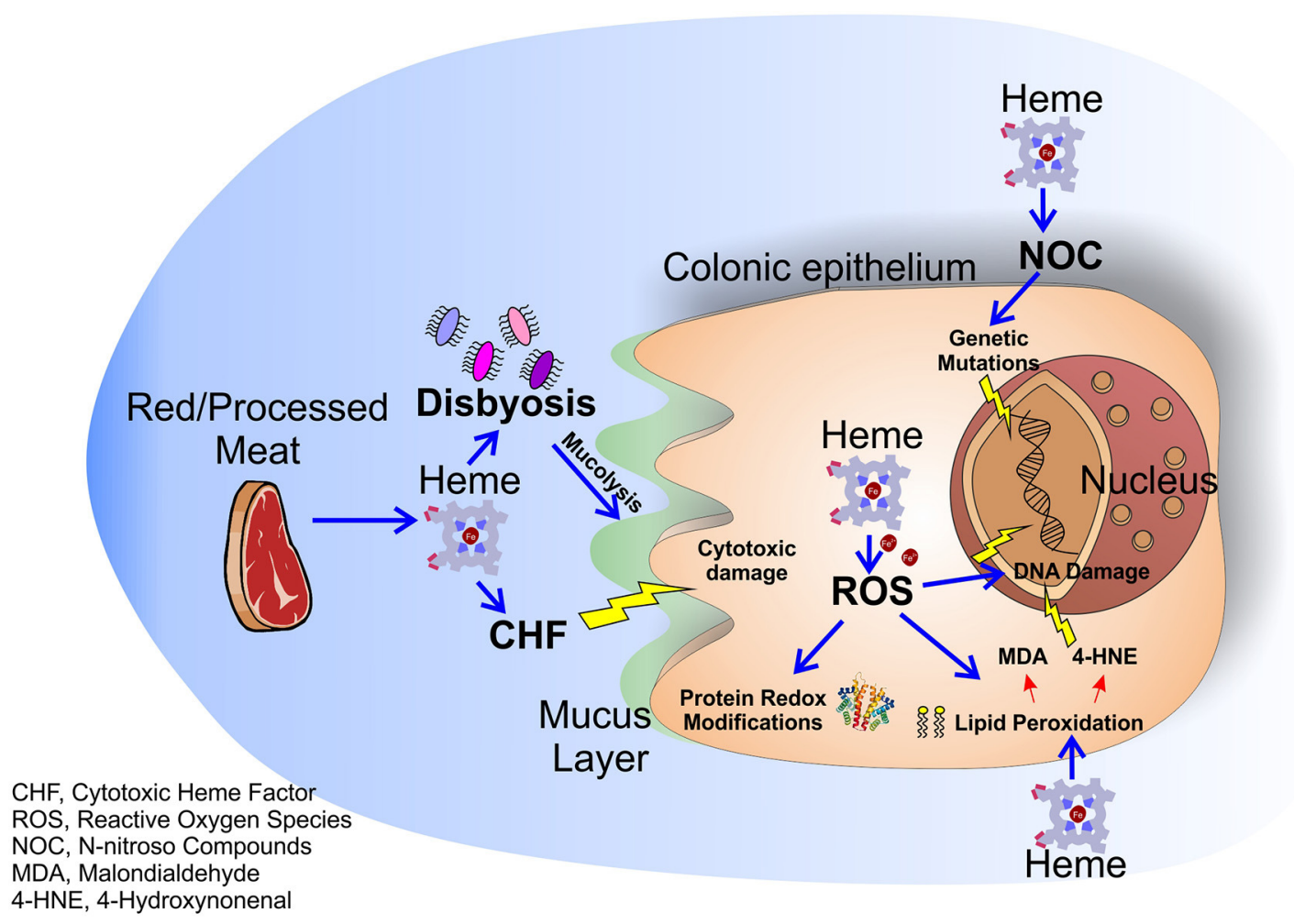

FIGURE 1 | Molecular mechanisms of dietary heme induced colorectal carcinogenesis. Heme in red/processed meat alters multiple molecular and genetic mechanisms in the colonic epithelium resulting in colorectal carcinogenesis. Heme accumulation induces the formation of the $\mathrm{CHF}$ that leads to cytotoxic damage to surface epithelial cells. Moreover, heme causes peroxidation of lipids and NOC formation resulting in free radical formation and genetic mutations. Labile iron, resulting from heme degradation, induces the formation of ROS that lead to oxidative damage and genetic mutations. Finally, heme alters the intestinal flora enhancing the heme-induced cytotoxic effects.

methodologies employed in some of these studies have been challenged. Indeed, some animal studies took advantage of diets low in calcium and high in fat, combined with the exposure of heme frequently at doses higher than that expected with a normal dietary consumption of red meat. Moreover, pork meat shows low heme levels, but it has been associated with CRC. Finally, it cannot be excluded that carcinogenesis could be ascribed to other molecules contained mostly in red meat, not related to heme (33). Therefore, further research is required to clarify the role of heme present in red and processed meat in cancer.

\section{HEME SYNTHESIS AND CANCER}

Heme can be acquired by dietary sources, but in addition, all the cells in the organism are able to synthesize heme. Heme synthesis includes eight different reactions occurring partly in mitochondria and partly in the cytosol. The first rate limiting step is based on the condensation of succynil-CoA and glycine to produce 5-aminolevulinic acid (ALA), a reaction catalyzed by the enzyme 5Amilolevulinate Synthase 1 (ALAS1). Then, by subsequent reactions involving the enzymes ALA dehydratase (ALAD), porphobilinogen deaminase (PBGD), uroporphyrinogen III synthase (UROS), uroporphyrinogen decarboxylase (UROD), coproporphyrinogen oxidase (CPOX), protoporphyrinogen oxidase (PPOX) and ferrochelatase (FECH), heme is finally produced $(4,39)$.

The study of heme synthesis in tumors has raised interest since many years. Indeed, in nineties, it was discovered that tumors, upon ALA administration, are able to accumulate remarkably higher amount of protoporphyrin IX (PpIX) as compared to normal tissues, and this property was demonstrated to be exploitable for tumor fluorescenceguided surgery (FGS) and to kill cancer cells by photodynamic therapy (PDT) (40-42). Since then, extensive research has been performed to determine the molecular mechanism involved in enhanced ALA-PpIX accumulation in tumor cells. Particularly, the rate of heme biosynthesis in different kinds of tumor was dissected in several works, leading to accumulation of conflicting results. However, ALAS1, PBGD and UROD expression and/or activity were frequently found up-regulated in cancer (43). Consistently, repression of heme biosynthesis by the ALAD inhibitor succinylacetone was shown to reduce tumor cell survival and proliferation (44-46). Conversely, FECH levels were found often down-modulated in tumor cells as compared to normal cells $(43,47)$. 
Taking together these discoveries, it can be concluded that tumors are characterized by high porphyrins synthesis, not necessarily associated to final heme production. This conclusion, however, is controversial. Indeed, cancer cells have been shown to display high heme levels $(45,48)$, increased activity of heme containing proteins $(45,46,49)$ and enhanced expression of heme exporters $(45,50)$, suggesting that heme, and not only its precursors, is produced and that the entire heme biosynthetic pathway is promoted in tumors. Therefore, the reason why tumors accumulate more ALA-mediated PpIX than surrounding normal tissues and why tumors enhance heme synthesis remains a fundamental question to be answered (Figure 2).

Considering the fact that heme is a crucial cofactor for complexes of the electron transport chain (ETC), one possible explanation for increased heme biosynthesis in tumors is that it could be exploited by cells to sustain oxidative phosphorylation (OXPHOS). Indeed, despite the well-accepted model proposed by Otto Warburg and co-workers, pointing to increased glycolysis in cancer cells, many lines of experimental evidence have shown that the function of mitochondrial OXPHOS in most tumors is intact and that the vast majority of tumor cells generate adenosine triphosphate (ATP) via oxidative phosphorylation (51). Data obtained on the human lung carcinoma cell line A549 showed that induction of heme biosynthesis by ALA enhances OXPHOS in these cells (52). Similarly, in additional studies on lung cancer (46) and in an in vitro model of myeloid leukemia (45), it was demonstrated that increased heme synthesis is associated to higher oxygen consumption, an indicator of OXPHOS, and the effect was prevented by cell treatment with succynilacetone.

Nevertheless, tumors like hereditary leiomyomatosis and renal-cell cancer (HLRCC), due to mutations in the tricarboxylic acid (TCA) cycle enzyme fumarate hydratase, show reduced OXPHOS and sustained glycolysis but increased heme synthesis (53). Similarly, human colon carcinomas overexpress the mitochondrial ATPase Inhibitory Factor 1 (ATPIF1), an inhibitor of the mitochondrial $\mathrm{H}^{+}$-ATP synthase (54) and OXPHOS, as well as a promoter of iron incorporation into PpIX by FECH (55). These studies support the idea that suppression of OXPHOS and enhanced glycolysis in tumors could be associated to increased heme biosynthesis, suggesting that heme can mediate additional functions in cancer, unrelated to its role as a cofactor for ETC complexes.

A complex interplay between heme and energy metabolism is further supported by studies indicating that ALAS1 expression is suppressed by glucose (56). Moreover, it has been recently reported that heme can negatively regulate the activity of pyruvate dehydrogenase (PDH) by binding the PDHA1 subunit, favoring a switch from pyruvate oxidation in the mitochondria to its glycolytic conversion into lactate (57). In addition, heme can control the trafficking of ADP and ATP between mitochondria and cytosol. The translocase involved in the ADP/ATP exchange is the adenine nucleotide transporter (ANT), an integral protein located in the inner mitochondrial membrane. While in rodents only three ANTs exist (ANT1, 2, and 4), in humans there are four ANT isoforms (ANT1, 2, 3, and 4), encoded by four distinct genes with different promoter sequences, supporting distinct regulatory control. In humans, ANT1 is mainly expressed in heart, skeletal muscle and brain, while ANT3 is ubiquitous (58) and ANT4 is expressed in testis and germ cells (58). Conversely, ANT2 is poorly detectable in tissues, but its expression can dramatically increase in cancer and proliferating cells with high glycolytic rates and/or low oxygen $(58,59)$. ANT1 and ANT3 export ATP synthesized in mitochondria toward the cytosol, while several evidences suggest that ANT2 may realize an inverse exchange, translocating the glycolytic ATP synthesized in the cytosol toward the mitochondrial matrix (59). Moreover, ANT1 and 3 are crucial component of the mitochondrial permeability transition pore complex and play a major role in mitochondria-mediated cell death (60-62). Heme binds ANT1, 2 , and 3 isoforms and ANTs are believed to contribute to heme biosynthesis by transporting heme precursors into mitochondria (63). Particularly for ANT1, it has been demonstrated that heme binds to the center pore domain and to the residues that associate to ADP, and binding of heme, or of the heme precursors PpIX and coproporphyrin III, inhibits the ADP uptake in a competitive manner (63). Moreover, heme can transcriptionally repress the expression of $\mathrm{ATP} / \mathrm{ADP}$ carrier (AAC) 3, the yeast ANT2 orthologous, through the ROX1 factor (64). Interestingly, human ANT2 promoter shows a negative regulatory motif, called glycolysis regulated box (GRBOX) that is a ROX1-like motif (59), suggesting possible heme-dependent regulation also of human ANT2. This could be particularly relevant in cancer, because ANT2 has been postulated to contribute to the rapid metabolic adaptation of tumor cells to glycolysis and hypoxic stress by preserving the mitochondrial ATP content necessary to maintain the mitochondrial membrane potential and intramitochondrial metabolic pathways when OXPHOS is impaired $(58,65)$. Moreover, additional studies have highlighted an antiapoptotic role for ANT2 (66), its implication in the PI3K/Akt pathway (67), frequently activated in cancer, and in the regulation of cancer-related microRNAs (67). Finally, ANT2 is considered a promising therapeutic target to control tumor cell growth, migration, invasion and chemosensitization (68). Therefore, the modulation of heme synthesis, by affecting ANTs activity and expression, could have consequences on the transport of both OXPHOS-derived ATP from mitochondria to cytosol or of glycolytic ATP from the cytosol to the mitochondria.

Overall, the role of heme synthesis in the modulation of cancer energy metabolism remains controversial.

Another possibility is that increased heme synthesis in tumors is intended to support the activity of specific hemoproteins. Cells are equipped with several hemoproteins (69) and for some of them a role in cancer has been reported, including myoglobin (70), tryptophan 2,3-dioxygenase (TDO) and indoleamine-2,3-dioxygenase 1 and 2 (IDO1/2) (71-73), mitochondrial cytochromes $(74,75)$, cytochrome P450 (76, $77)$, and cyclooxygenases $(78,79)$. Studies on lung cancer demonstrated that the amount of oxygen-utilizing hemoproteins, such as cytoglobin, cytochrome c, cytochrome P450 family 1 subfamily B member 1 (CYP1B1) and prostaglandinendoperoxide synthase 2 (COX2) are higher in tumor cells as compared to normal cells and that, at least for cytoglobin and cytochrome $\mathrm{c}$, their levels depend on the rate of heme synthesis 


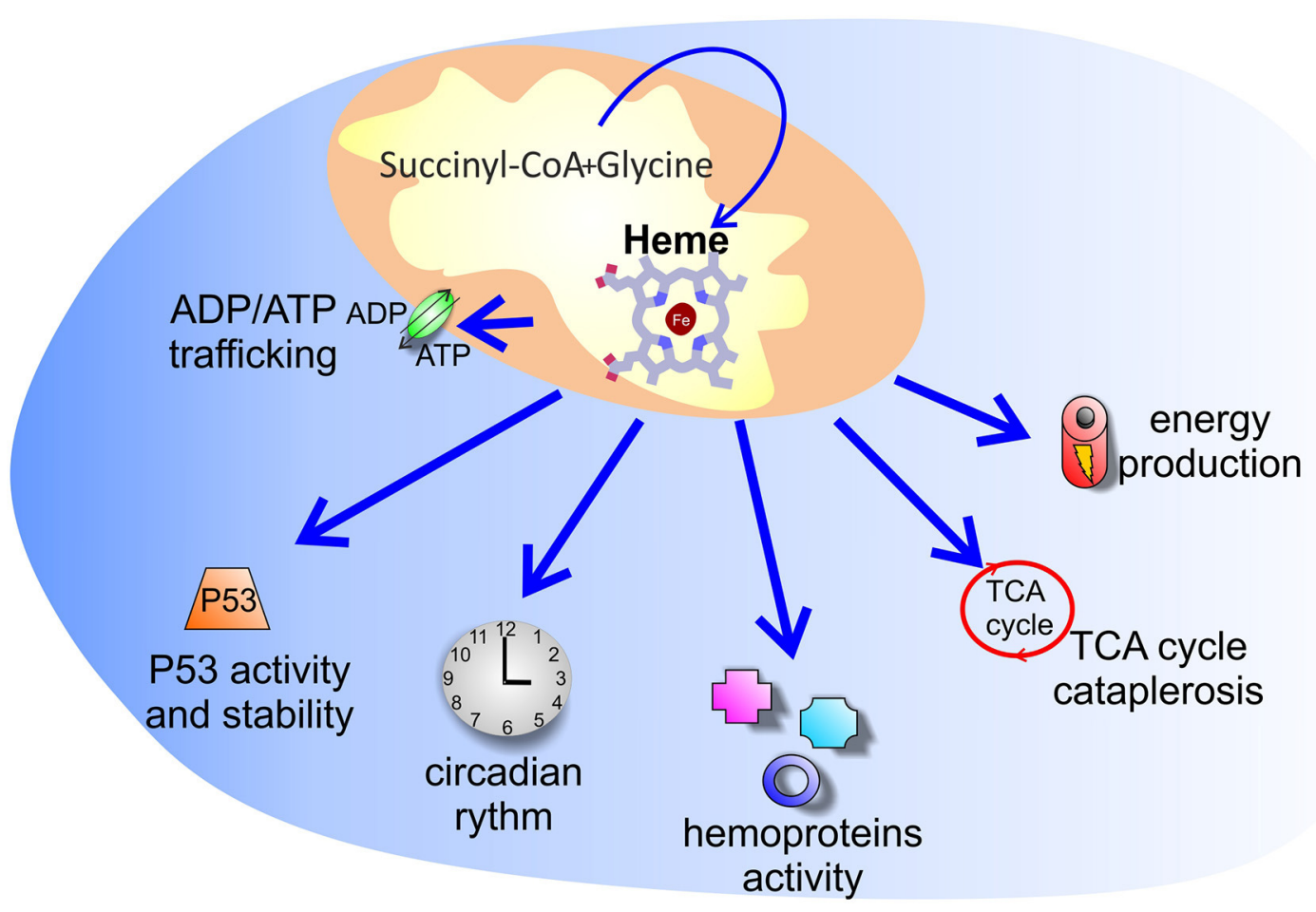

FIGURE 2 | Putative processes controlled by increased heme synthesis in cancer. The reason why tumors enhance heme synthesis is unknown. Several hypotheses have been explored: increased heme synthesis could control energy production, ADP/ATP exchange between mitochondria and cytosol, TCA cycle cataplerosis, P53 activity and stability, as well as the activity of hemoproteins and of heme binding proteins involved in the circadian clock machinery.

\section{Tumor microenvironment}

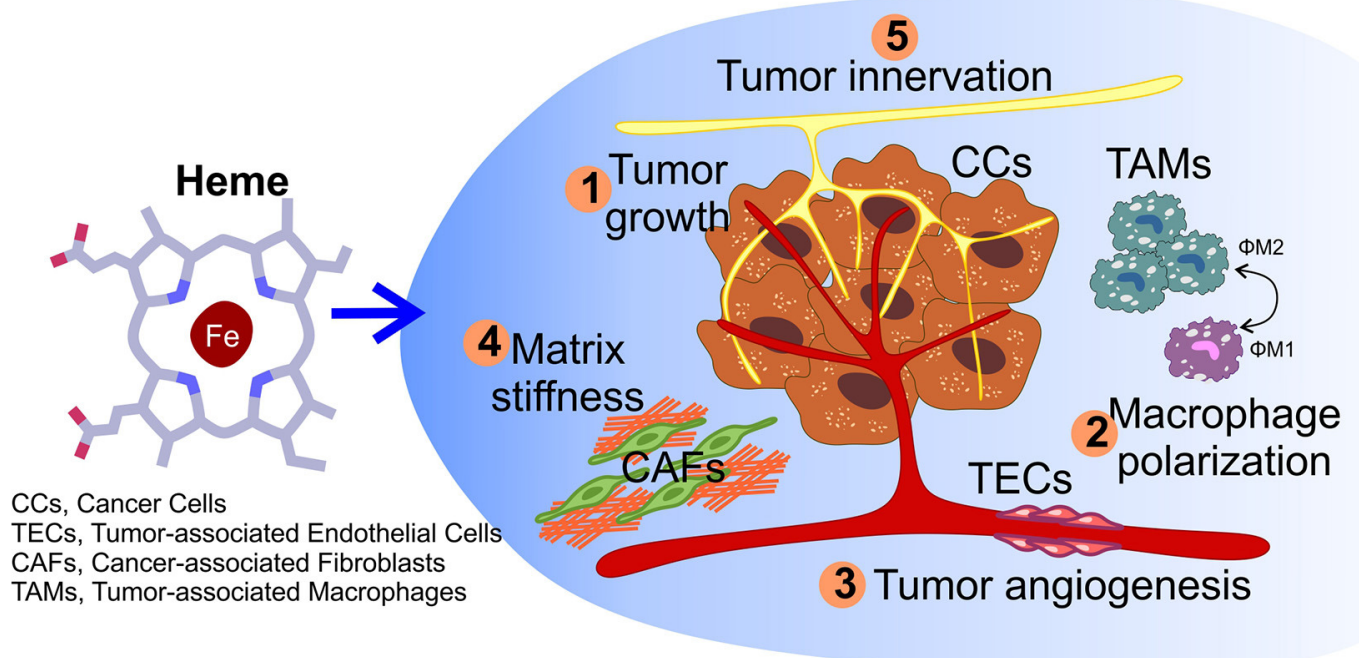

FIGURE 3 | Impact of heme on tumor microenvironment. Other than sustaining cancer cells growth (1), heme could also potentially affect other processes within the microenvironment, including macrophage polarization (2), the angiogenic potential of tumor endothelial cells (3), matrix remodeling by cancer-associated fibroblasts (4), and nerve-cancer cross-talk (5).

and cellular heme content (46). A similar phenotype was observed in human non-small cell lung cancer (NSCLC) tissues (49). Moreover, in colorectal cancer cells ALA administration results in the down-modulation of cyclooxygenase 2 expression, although its overall enzymatic activity is maintained (80). These hemoproteins can control oxygen availability or participate in 
crucial metabolic processes tightly modulated in cancer cells to allow/promote cell survival and proliferation, as well as to escape tumor immunosurveillance. Furthermore, heme can interact and regulate the activity of additional proteins with an already reported role in cancer. For example, heme is a crucial regulator of the nuclear receptor subfamily 1 group $\mathrm{D}$ member 1 (NR1D1 or Rev-erb $\alpha$ ) (81), as well as an interactor for neuronal PAS domain protein 2 (NPAS2) (82) and period circadian regulator 2 (PER2) $(83,84)$. All these proteins are involved in the circadian clock mechanism, and alterations in circadian rhythm is typically observed in cancer, so that some of the clock machinery components have been proposed as targets in cancer therapy (85). Therefore, heme synthesis promotion in tumor cells could also partly contribute to modulate this system in order to sustain cell growth.

In addition, increased heme synthesis in cancer cells may be promoted in order to regulate the tumor suppressor P53, a transcription factor that controls a broad and flexible network of biological processes, including DNA damage response, autophagy, cellular metabolism, epigenetics, inflammation, just to cite the most relevant ones (86). Interestingly, Shen et al. (87) demonstrated that the stability of P53 is directly regulated by heme. Indeed, heme binds to a C-terminal heme-responsive motif (HRM) of P53. The heme-P53 interaction interferes with the P53 DNA binding activity in vitro, thus suggesting that heme may modulate the transcription of P53 target genes. Furthermore, the binding of heme to P53 promotes its nuclear export and degradation via the ubiquitin-proteasome system. These findings provide mechanistic insights into the process of tumorigenesis associated with iron excess. It is well-established that iron excess is a hallmark of several tumor types (88). A positive correlation between iron and heme levels in vivo has been reported (87), leading to the hypothesis that iron excess in cancer sustains the synthesis of heme, that in turn directly affects P53 stability and function. Considering the increasing amount of data showing that tumors reprogram heme metabolism (not only iron metabolism) to achieve advantages in terms of proliferation and survival, it is tempting to propose that the alteration of heme metabolism that occurs during tumor onset and cancer progression may contribute to the dysregulation of P53 expression.

In the end, it has been proposed that heme synthesis is enhanced in cancer in order to mediate TCA cycle cataplerosis. By this view, enhanced heme biosynthesis is primarily intended to consume succynil-CoA rather than to produce heme. In HLRCC it has been demonstrated that increased heme biosynthesis is crucial to avoid the accumulation of toxic TCA cycle intermediates, as a consequence of mutations in fumarate hydratase. Heme produced in this system is then addressed to degradation by the enzyme HMOX1, indicating that its production is not intended to increase the intracellular bioavailable heme pool (53).

Overall, it seems clear that heme biosynthesis is frequently enhanced in tumors and that this phenomenon could serve different and sometimes conflicting purposes. Additional studies are required to fully elucidate the underlying mechanism that can reconcile all these aspects.

\section{HEME IMPORT/EXPORT/DEGRADATION AND CANCER}

Other than being synthesized, heme can also be imported inside the cell by three main importers: (1) the solute carrier family 46 member 1 (SLC46A1 or HCP1), a folate importer able to transport also heme, (2) the feline leukemia virus subgroup $\mathrm{C}$ receptor family member 2 (FLVCR2), and (3) the solute carrier family 48 member 1 (SLC48A1 or HRG1). Among them, FLVCR2 and HCP1 are exposed on the cell plasma membrane, while HRG1 is localized on endolysosomes.

The role of FLVCR2 in normal cells is not well-studied and to our knowledge there is only one paper to date in which FLVCR2 was analyzed in cancer. In this paper, interestingly, it was observed that FLVCR2 is overexpressed in bovine papillomavirus-associated urinary bladder cancer (89).

Regarding HCP1 and HRG1, their levels were reported to be dramatically increased in lung cancer cells/tissues $(46,49)$, where they contribute to import heme in order to ensure proper activity of hemoproteins. Indeed, depletion of heme in the culture medium of tumor cells or the use of heme-sequestering peptides, to avoid heme uptake, result in the down-modulation of hemoproteins activity $(46,49)$. In addition, high expression of $\mathrm{HCP} 1$ was detected in gastric cancer cells as compared to normal gastric cells (90). Moreover, HRG1 overexpression was observed in HeLa cells and in highly invasive and migratory cancer cell lines, where it can be detected not only in endolysosomes but also on the cell plasma membrane. Its silencing in these cells was demonstrated to result in reduced survival and migratory capacity, while the opposite phenotype was observed upon its over-expression $(91,92)$. In HeLa cells it was demonstrated that HRG1 interacts with the vacuolar $\mathrm{H}^{+}$-ATPase and regulates its activity, thus modulating the acidification of endosomes (91). By this way, HRG1 has a unique role in regulating $\mathrm{pH}$ dependent endocytic pathway, with an impact on the ability of the cells to acquire nutrients, to mediate signaling in response to growth factor receptor activation, and to internalize and traffic integrins and other proteins, which is necessary for cell survival, migration, and proliferation (91). Moreover, in additional highly invasive and migratory cancer cell lines, it was shown that, by the interaction with the vacuolar $\mathrm{H}^{+}$-ATPase, HRG1 participates to the regulation of cytosolic/extracellular $\mathrm{pH}$ gradient. Indeed, HRG1 indirectly favors the alkalinisation of cell cytosol and the acidification of the extracellular environment, a condition that enhances extracellular matrix degrading enzymes expression and activity, facilitating a more invasive phenotype of cancer cells (92). In addition HRG1 expression in these cells was associated to a $\mathrm{pH}$-dependent promotion of glucose transporter 1 (GLUT1) trafficking to the plasma membrane, leading to increased glucose uptake and glycolysis, thus favoring cell growth (92).

Altogether, these studies indicate that heme import is enhanced in cancer with the aim to promote the activity of specific hemoproteins and to modulate $\mathrm{pH}$ gradient and cell metabolism.

Together with heme import, also heme export has been shown to be increased in cancer. Heme export is mediated by the specific heme exporter feline leukemia virus subgroup $\mathrm{C}$ 
receptor family member 1 (FLVCR1). Moreover, the ATP binding cassette subfamily G member 2 (ABCG2), a known exporter for a broad range of molecules and xenobiotics, is also involved in heme/porphyrins export.

The expression of FLVCR1 has been reported up-regulated in different kinds of tumors, including bovine papillomavirusassociated urinary bladder cancer (89), synovial sarcoma (50), and hepatocellular carcinoma (93). For hepatocellular carcinoma, the high expression of FLVCR1 was associated to higher neoplasm disease staging, adjacent tissue inflammation, vascular invasion and neoplasm histologic grade, as well as to reduced overall survival and disease-free status (93). In synovial sarcoma cells, the silencing of FLVCR1 was associated to reduced cell proliferation, survival and tumorigenicity in vitro and in vivo (50). Similarly, FLVCR1 silencing impairs the survival of neuroblastoma cells in vitro, particularly upon ALA administration (94).

The literature on ABCG2 and cancer is very rich; however, it is important to distinguish between its role as a heme/porphyrins exporter as compared to its role in the efflux of additional unrelated substrates and xenobiotics. Focusing on heme, it has been shown that triple negative breast cancer cell lines have significantly reduced ALA-PpIX levels as compared with estrogen receptor (ER) positive and human epidermal growth factor receptor 2 (HER2) positive breast cancer cell lines because of elevated ABCG2 activity (95). In line with this, high ABCG2 expression was considered a major cause of failure of ALAphotodynamic therapy in different kinds of tumors, as it can induce resistance to this kind of treatment by preventing the accumulation of the photosensitizer PpIX inside the cells $(96,97)$. Moreover, in an in vitro model of myeloid leukemia, it has been shown that MYCN drives increased heme synthesis and that, in this system, the excess of PpIX produced is promptly exported out of the cells by ABCG2 to avoid cell toxicity (45). Therefore, in these cells the forced stimulation of heme synthesis, associated with the imposed reduction of ABCG2 expression, leads to tumor cell death.

Overall, the literature on heme import and export in cancer looks counterintuitive, indicating that both processes are enhanced in tumor cells. Although an explanation for these apparently conflicting phenomena does not exist, it could be postulated that the two systems are both promoted in order to establish a new equilibrium in heme homeostasis. Another possibility is that import and export target two different pools of heme, and that cellular heme compartmentalization could play a role in this context. Interestingly, it has been shown that heme export by FLVCR1 is highly associated to heme synthesis (98), thus supporting the idea that the trafficking of endogenously synthesized heme could be managed differently as compared to exogenous heme imported into the cells. Additional studies are required to fully elucidate the biological significance for these alterations of heme trafficking in cancer.

Finally, intracellular heme homeostasis benefits of an additional system to control heme levels, which is the degradation of the molecule. As described above, HMOXs, the ratelimiting enzymes in heme catabolism, catalyze the stereospecific degradation of heme to biliverdin, with the concurrent release of ferrous iron ions and CO. There are two main HMOXs isoforms, encoded by two distinct genes: HMOX1 and HMOX2. HMOX2 is a constitutively expressed protein, while HMOX1 can be strongly induced in many tissues in response to cellular stress caused by a wide spectrum of stimuli including, but not restricted to, heme. The literature on HMOXs and cancer is wide, and a comprehensive summary of works on this topic can be found in several reviews (99-101). Nevertheless, also in this case it is important to distinguish between HMOXs role as heme degrading enzymes as compared to their noncatalytic role. Indeed, it has been shown that enzymatically inactive HMOX1 could translocate to the cell nucleus and exerts gene expression regulatory functions $(102,103)$. The role of HMOX1 in tumor cell proliferation is controversial: its expression in tumors was found very frequently up-regulated and a role for HMOX1 as a mediator of ROS-promoted cell proliferation was established; on the other hand, however, in other kinds of tumors an HMOX1 anti-proliferative action was demonstrated, often associated to effects mediated by $\mathrm{CO}$ and biliverdin $(99,101)$. However, most experiments support a permissive role of HMOX1 in tumor growth. What seems to be clear is that HMOX1 can affect different aspects of tumorigenesis, encompassing regulation of cell proliferation and differentiation, promotion of cytoprotection and inhibition of apoptosis, induction of angiogenesis and metastatization, as well as immunosuppression (99-101). Moreover, HMOX1 activity may affect anti-tumor therapies, as its expression is further elevated in response to radio-, chemo-, or photodynamic therapy and is involved in resistance to them $(100,101)$. Summarizing, the expression of HMOX1 and the activity of its byproducts can provide the selective advantage for tumor cells to overcome the increased oxidative stress occurring during tumorigenesis and/or as a consequence of anti-tumor therapies.

\section{HEME AND TUMOR MICROENVIRONMENT}

Other than acting directly on tumor cells, heme can exerts its functions in cancer by modulating the tumor microenvironment (TME) (Figure 3). The TME is composed by tumor cells, endothelial cells of surrounding blood vessels, myofibroblasts, stellate cells, adipose cells, peritumor nerve cells, immune cells, endocrine cells, fibroblasts, and the extracellular matrix $(104,105)$. All the cell types in the TME contribute to tumor progression mainly by releasing factors, which establish a favorable environment for the cancer cell and promote tumor cell survival and migration, metastasis formation, chemo-resistance, and the ability to evade the immune system responses (104).

Heme has been reported to modulate the activity of tumor-associated macrophages (TAMs). Macrophages have heterogeneous phenotypes that range from the "classicallyactivated" pro-inflammatory M1-cells to the "alternativelyactivated" anti-inflammatory M2-cells (106). If on one hand M1like macrophages have anti-tumor properties, on the other hand macrophage polarization toward a M2-like phenotype correlates with pro-tumor activities, such as enhanced angiogenesis, matrix remodeling, and immune suppression $(107,108)$. Due to the 


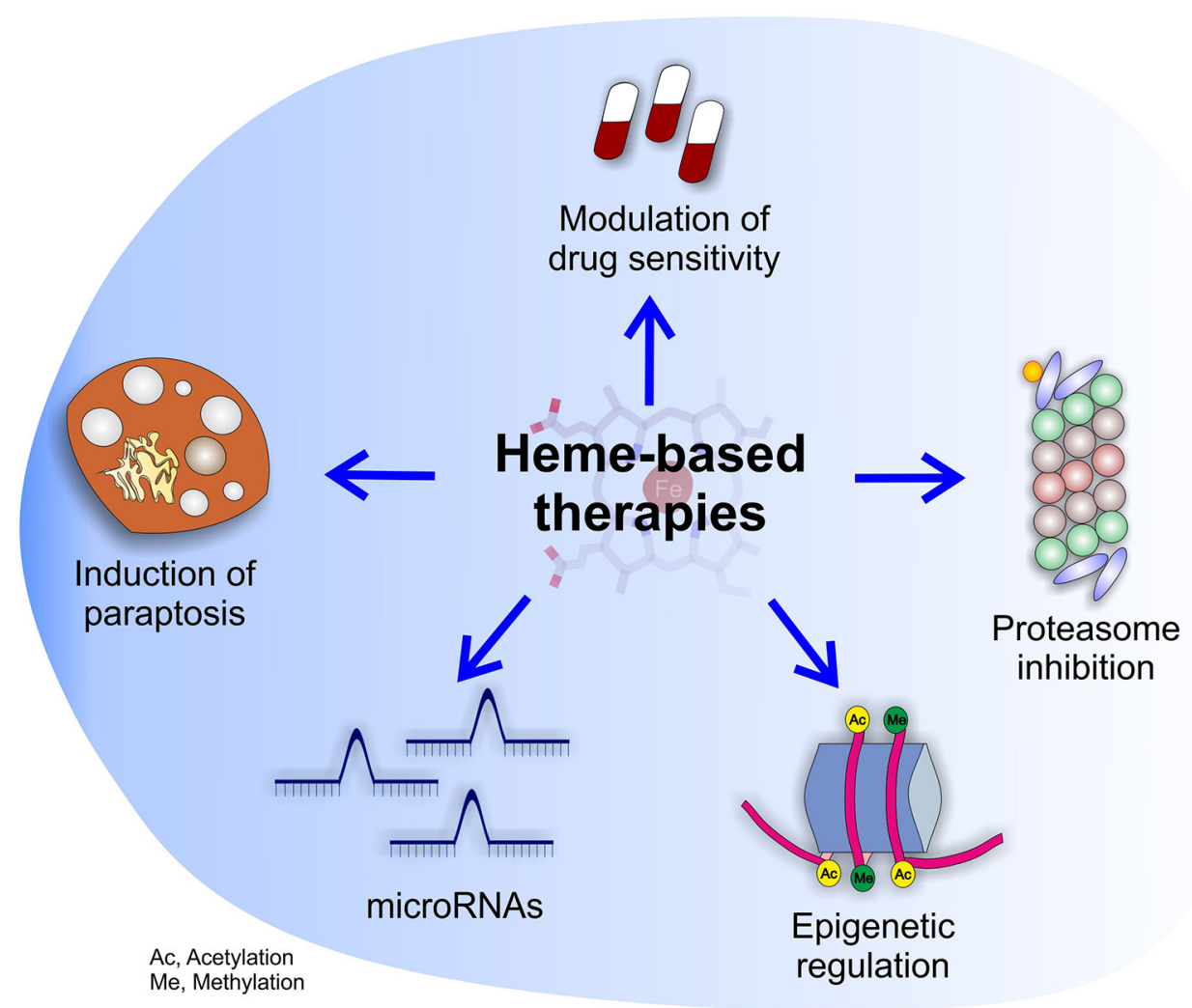

FIGURE 4 | Potential effects of heme-based therapies. The multifaceted role of heme in cancer suggests the possibility to develop novel therapies targeting heme metabolism. The picture highlights the potential beneficial effects of heme-based therapies on cancer cells as well as tumor microenvironment.

specific cues that characterize the tumor microenvironment, TAMs are induced to preferentially acquire a M2-like specialized phenotype that protects cancer cells from targeted immune responses (109). Notably, M. Costa da Silva and colleagues demonstrated that TAMs exposed to haemolytic red blood cells (RBCs), a condition sometimes observed in cancer due to the extravasation of RBCs from the abnormal tumor-associated vessels (110), accumulate iron intracellularly and acquire a M1 pro-inflammatory phenotype, which in turn promotes tumor cell death (111). This is in line with studies on haemolytic diseases, such as sickle cell disease, where it has been observed that macrophage exposure to free heme, released by damaged erythrocytes, leads to M1-reprogramming (112). Moreover, these findings are in agreement with additional studies reporting the concept that iron can drive macrophages polarization toward a pro-inflammatory M1-phenotype $(113,114)$. The effects on TAMs described can be mainly ascribed to the iron atom contained in heme. However, another important aspect that should be taken into account is the role exerted by $\mathrm{CO}$ in the control of myeloid cell differentiation. Indeed, the CO produced upon heme degradation by HMOXs has been reported to cause tumor regression and increased drug sensitivity in prostate and lung cancer models (115), and this can be partly attributed to CO effects on macrophages within the TME. Specifically, it has been shown that $\mathrm{CO}$ treatment in mice leads to an increased number of M1-like macrophages and reduced tumor growth (116). Taken together, these works have led to the implementation of strategies able to modulate the exposure of macrophages to heme or iron, as the use of iron oxide nanoparticles $(109,111)$, for cancer therapy.

Another fundamental component of the tumor microenvironment is represented by tumor-associated endothelial cells (TECs). TECs strongly differ from their normal counterparts (117) as they display a high pro-angiogenic potential that mostly relies on their enhanced ability to proliferate and migrate. The switch of TECs from quiescence to a highly active state is favored by a specific metabolic reprogramming (118-120). The cross-talk between cancer cells and TECs promotes aberrant neo-angiogenesis, which is required to sustain tumor growth, by providing oxygen and nutrients, and to favor metastatization $(117,121,122)$. To our knowledge, there are no studies in literature analyzing the role of heme in TECs. However, we demonstrated that alterations in endothelial intracellular heme metabolism strongly affect the angiogenic process during development $(98,123)$. Consistently, another study highlighted the critical role of the heme biosynthetic pathway in supporting endothelial functions (124). In addition, tumor angiogenesis is also promoted by the increased stiffness of the extracellular matrix (ECM) found in TME $(125,126)$. High ECM stiffness is mainly due to increased collagen deposition and increased cross-linking within the 
tumor stroma. Matrix remodeling is primarily controlled by the activity of a group of zinc-dependent endopeptidases, named matrix metalloproteinases (MMPs), which are mainly released by cancer-associated fibroblasts (CAFs). However, recent studies highlighted the involvement in this process of peroxidases released by immune cells, such as myeloperoxidase (MPO) and eosinophil peroxidase (EPO). In particular, MPOs and EPOs have been reported to be able to directly induce the secretion of collagen I and collagen VI by CAFs (127), thus increasing matrix stiffness and promoting tumor angiogenesis and metastatization (128). Notably, MPOs and EPOs are heme-containing enzymes, thus suggesting that changes in the amount of available heme within the cells could affect the activity of these enzymes in matrix remodeling. Taking together all these considerations, it is tempting to speculate that heme could affect different processes involved in tumor angiogenesis and future studies will help to verify this hypothesis.

Finally, an additional promising aspect to dissect in the future is the possible implication of heme in the control of tumor innervation. The peripheral nervous system is nowadays gaining growing interest in cancer research due to its role in modulating both cancer cells and TME. This is achieved through the reciprocal interaction between nerves and cancer cells (nerve-cancer cell cross-talk), as well as between nerves and the TME (129-131). Indeed, recent data clearly indicate that tumor onset and progression is accompanied by increased innervation, through a mechanism largely dependent on the secretion of neurotrophic factors by cancer cells. Furthermore, nerves influence tumor onset, progression and metastasis formation, mainly through the secretion of neuropeptides and neurotransmitters in TME, where they interact with receptors expressed by cancer cells and by other cells of the TME (131136). Heme is required for the survival of different types of neuronal cells $(137,138)$; however, the specific role of heme in the peripheral nervous system and its potential implication in tumor innervation is completely unknown. Several evidences suggest that heme is crucial for the maintenance of the peripheral nervous system, particularly for sensory neurons, one of the types of nerves that actively innervates tumors (139-141). Notably, mutations in genes encoding proteins involved in heme synthesis and export have been reported in diseases characterized by the degeneration of sensory neurons $(94,142-$ 145). Finally, heme may also regulates pathways important for nerve-cancer cell cross-talk. Indeed, heme is involved in the regulation of gene expression in neurons via nerve growth factor (NGF) signaling (146), thus suggesting that heme may modulate nerve outgrowth in the tumor microenvironment. Furthermore, heme also regulates the metabolism of some neurosteroids and neurotransmitters (137), with a potential implication in nerve-cancer cross-talk. In addition, other than sustaining cancer, tumor innervation is also one of the main cause of chronic pain in oncologic patients, particularly those in the advanced stage of the disease $(147,148)$. Interestingly, mutations in the heme exporter FLVCR1 have been reported in patients with peripheral sensory neuropathy $(94,149,150)$, thus indicating an involvement of heme in pain perception. Furthermore, $\mathrm{CO}$ produced upon heme catabolism can act as an atypical neurotransmitter or neuromodulator in the nervous system and is involved in nociception regulation (151). Overall, these evidences support the idea that heme could be implicated in different aspects of tumor innervation. Future targeted in vitro and in vivo experiments will definitively verify whether this hypothesis is correct.

\section{ADDITIONAL HEME FUNCTIONS POTENTIALLY RELEVANT FOR CANCER}

In the previous paragraphs, we discussed the works that contributed to explore the role of heme in tumor growth and metastatization. However, we believe that heme could be involved in additional aspects of tumor biology, not investigated so far. Indeed, emerging evidences indicate that heme is required for the processing of microRNA (miRNA) that, by regulating more than $50 \%$ of the mammalian genome are implicated in several pathways crucial for cancer onset, growth and metastatization (152). Specifically, the RNA-binding protein DiGeorge critical region-8 (DGCR8), which is essential for the first processing step of pri-miRNAs, is a heme-binding protein (153-156). Heme binding to DGCR8 is required for its dimerization and activation (153) and the modulation of heme availability was reported to affect pri-miRNA processing in vitro (157). A correlation between alterations of heme and miRNAs expression was also reported. For instance, ALA-mediated sonodynamic therapy or PDT is associated with the altered expression of selected miRNAs (158-161). Although, further studies are required to fully understand the physio-pathological implications of these findings, these data suggest that mysregulation of miRNAs may represent an additional mechanism through which alterations of heme metabolism sustain and promote cancer progression.

In addition, several data support a potential involvement of heme in epigenetic modifications, that control multiple processes essential for cancer cells $(162,163)$. This is suggested by the observation that heme regulates the transcriptional and demethylase activity of the yeast histone demethylase GIS1 (GIS1), that belongs to the lysine demethylase 4 (jmjd-2/KDM4) subfamily of demethylases implicated in histone methylation, cellular signaling and tumorigenesis (164). The yeast GIS1 protein is conserved from yeast to mammals, suggesting a possible role for heme in the regulation of this protein also in mammals. Furthermore, several heme-regulated proteins of the circadian rhythms machinery are epigenetic modifying enzymes themself. For instance, clock circadian regulator (CLOCK) is a histone acetyltransferase and Rev-erb $\alpha$ functions as a transcriptional repressor by forming a complex with the nuclear receptor corepressor (NCOR) and the histone deacetylase 3 (HDAC3) (165). Finally, the activity of epigenetic modifying enzymes relies on the availability of specific metabolites (like $\alpha$ ketoglutarate) and cofactors (acetyl-CoA, S-adenosylmethionine, and nicotinamide adenine dinucleotide). Most of them are produced by the TCA cycle. Since heme biosynthesis is a TCA cycle cataplerotic pathway (166), it is reasonable that alterations of heme homeostasis may affect the availability of metabolites to epigenetic modifying enzymes. Based on the role of heme in 
the control of cellular metabolism (166) and circadian rhythms (81), we propose that the alterations of heme metabolism observed in cancer may also contribute to the mysregulation of cancer epigenetics.

Finally, heme metabolism has been reported as an apoptosis modifying pathway in acute myeloid leukemia (AML) (167). This is relevant, because it suggests the possibility to target heme metabolism in order to increase drug sensitivity in cancer cells. In addition, we observed that the modulation of heme metabolism induces paraptosis (123), at least in endothelial cells. This suggests the possibility to potentially exploit the regulation of heme metabolism in cancer therapy, as the availability of compounds inducing alternative forms of programmed cell death could be very useful to counteract the resistance to apoptosis in tumors (168). Similarly, the identification of heme as an inhibitor of the proteasome (169) appears as a promising property to be exploited for therapeutic purposes, particularly considering that proteosome inhibitors are successfully currently used in cancer therapy (170).

\section{CONCLUSIONS}

By the present review, we attempted to provide a comprehensive overview of the literature on heme in cancer, highlighting heme participation in multiple processes that sustain tumor growth and metastatization, encompassing the control of mitochondrial metabolism, the function of hemoproteins and P53 signaling.

Summarizing, the studies on dietary heme and cancer, although affected by some limitations, support the idea that heme contained in food can sustain cancer by different mechanisms. Conversely, the impact of endogenous heme in cancer is much more complex to envisage. On the one hand, heme biosynthesis is frequently enhanced in tumors, but this phenomenon could serve different and sometimes conflicting purposes. Moreover, both heme import and export are increased in tumor cells, but the reason is unclear. In addition, heme degradation by HMOX1 in tumor cells seems to support cancer by counteracting oxidative stress during tumorigenesis and upon anti-tumor therapies, but concomitantly to promote TAMs acquisition of a M1-like phenotype, favoring tumor regression and increased drug sensitivity. Finally, heme-containing enzymes like MPOs and EPOs can promote tumor angiogenesis and metastatization, and heme could also potentially affect cancer epigenetics, miRNAs and tumor innervation. Therefore, targeting heme metabolism is promising because it could have a broad impact on different aspects of cancer. For this reason, we envision that future work should be directed to the development of novel therapeutic strategies based on heme (Figure 4). However, the choice of the appropriate strategy is challenging, due to possible conflicting effects obtained by the block or the promotion of heme-related processes. To overcome these problems, further work is required in order to classify the precise tumor subtypes that can benefit of each single strategy.
Anyhow, according to present literature, the targeting of heme metabolism has already been exploited for cancer therapy. In particular, the stimulation of heme synthesis with ALA has been widely used for PDT (171). In addition, the indirect inhibition of heme synthesis through iron chelation therapy has been recently proposed for selected cancer types. Iron chelation therapy has emerged as an important chemotherapeutic strategy, because of the strong link between iron excess and tumorigenesis. However, iron-deprivation therapy was successful only on selected tumor types. The discovery that heme directly regulates P53 stability (87) explained the selective therapeutic efficacy of iron deprivation-based chemotherapy. Indeed, Shen et al. demonstrated that this selectivity was due to the P53 status of the tumor types (87). Specifically, iron chelation therapy, by decreasing heme levels, leads to the stabilization of P53 proteins only in tumors with wild-type P53, and not in case of P53 mutations. As already suggested by Shen et al., these findings will allow the discrimination of the types of tumor that should benefit of iron chelation therapy (87). The targeting of heme synthesis through the deprivation of iron required for heme synthesis (iron chelation therapy) remains the best therapeutic strategy to date. However, because iron is essential for multiple processes beyond heme synthesis, a key challenge of chelation therapy is to balance iron levels in order to avoid excessive iron chelation. Moreover, it has to be underlined that emerging studies demonstrate that some kinds of tumor could be counteracted by iron supplementation, rather than by iron chelation therapy (172). Therefore, more specific strategies to blunt heme synthesis are required, not based on iron. The discovery that the beneficial effects of iron-chelation therapy on the growth of certain tumor types depends on the regulation of P53 by heme raises the possibility to directly target heme synthesis to counteract tumor growth. Several compounds, like succinylacetone or $\mathrm{N}$-methyl protoporphyrin, are used to inhibit heme synthesis in vitro. Although these compounds are not yet used in the clinic, we cannot exclude that new drugs based on them will be developed. Similarly, it could be possible that, in the future, drugs aimed at blocking/stimulating heme importer/exporter/degrading proteins will be identified, in order to perturb heme-related mechanisms in cancer.

In conclusion, we hope that, in the next future, the growing awareness on heme role in processes relevant for cancer will stimulate research aimed at implementing innovative therapeutic approaches and at identifying the tumor subtypes sensitive to these treatments.

\section{AUTHOR CONTRIBUTIONS}

VF, DC, SP, and FB wrote the manuscript. ET critically revised the manuscript intellectual content.

\section{FUNDING}

This work was supported by the Italian Association for Cancer Research (AIRC) IG18857 to ET. 


\section{REFERENCES}

1. Jung $M$, Mertens C, Tomat E, Brüne B. Iron as a central player and promising target in cancer progression. Int J Mol Sci. (2019) 20:E273. doi: 10.3390/ijms20020273

2. Wang Y, Yu L, Ding J, Chen Y. Iron metabolism in cancer. Int J Mol Sci. (2018) 20:95. doi: 10.3390/ijms20010095

3. Torti SV, Manz DH, Paul BT, Blanchette-Farra N, Torti FM. iron and cancer. Annu Rev Nutr. (2018) 38:97-125. doi: 10.1146/annurev-nutr-082117-051732

4. Chiabrando D, Vinchi F, Fiorito V, Mercurio S, Tolosano E. Heme in pathophysiology:a matter of scavenging, metabolism and trafficking across cell membranes. Front Pharmacol. (2014) 5:61. doi: 10.3389/fphar.2014.00061

5. Tolosano E, Fagoonee S, Morello N, Vinchi F, Fiorito V. Heme scavenging and the other facets of hemopexin. Antioxid Redox Signal. (2010) 12:305-20. doi: 10.1089/ars.2009.2787

6. Bouvard V, Loomis D, Guyton KZ, Grosse Y, Ghissassi FE, Benbrahim-Tallaa $\mathrm{L}$, et al. International agency for research on cancer monograph working group. carcinogenicity of consumption of red and processed meat. Lancet Oncol. (2015) 16:1599-600. doi: 10.1016/S1470-2045(15)00444-1

7. Sesink AL, Termont DS, Kleibeuker JH, Van der Meer R. Red meat and colon cancer; the cytotoxic and hyperproliferative effects of dietary heme. Cancer Res. (1999) 59:5704-9. doi: 10.1016/S0016-5085(98)82775-3

8. Willett WC, Stampfer MJ, Colditz GA, Rosner BA, Speizer FE. Relation of meat, fat, and fiber intake to the risk of colon cancer in a prospective study among women. N Engl J Med. (1990) 323:1664-72. doi: 10.1056/NEJM199012133232404

9. Giovannucci E, Rimm EB, Stampfer MJ, Colditz GA, Ascherio A, Willett WC. Intake of fat, meat, and fiber in relation to risk of colon cancer in men. Cancer Res. (1994) 54:2390-7.

10. Cross AJ, Freedman ND, Ren J, Ward MH, Hollenbeck AR, Schatzkin A, et al. Meat consumption and risk of esophageal and gastric cancer in a large prospective study. Am J Gastroenterol. (2011) 106:432-42. doi: 10.1038/ajg.2010.415

11. Inoue-Choi M, Sinha R, Gierach GL, Ward MH. Red and processed meat, nitrite, and heme iron intakes and postmenopausal breast cancer risk in the NIH-AARP diet and health study. Int J Cancer. (2016) 138:1609-18. doi: 10.1002/ijc.29901

12. Chang VC, Cotterchio M, Khoo E. Iron intake, body iron status, and risk of breast cancer:a systematic review and meta-analysis. BMC Cancer. (2019) 19:543. doi: 10.1186/s12885-019-5642-0

13. Genkinger JM, Friberg E, Goldbohm RA, Wolk A. Long-term dietary heme iron and red meat intake in relation to endometrial cancer risk. Am J Clin Nutr. (2012) 96:848-54. doi: 10.3945/ajcn.112.039537

14. Lam TK, Cross AJ, Consonni D, Randi G, Bagnardi V, Bertazzi PA, et al. Intakes of red meat, processed meat, and meat mutagens increase lung cancer risk. Cancer Res. (2009) 69:932-9. doi: 10.1158/0008-5472.CAN-08-3162

15. Taunk P, Hecht E, Stolzenberg-Solomon R. Are meat and heme iron intake associated with pancreatic cancer? Results from the NIH-AARP diet and health cohort. Int J Cancer. (2016) 138:2172-89. doi: 10.1002/ijc. 29964

16. Jakszyn P, González CA, Luján-Barroso L, Ros MM, Bueno-de-Mesquita HB, Roswall N, et al. Red meat, dietary nitrosamines, and heme iron and risk of bladder cancer in the European Prospective Investigation into Cancer and Nutrition (EPIC). Cancer Epidemiol Biomarkers Prev. (2011) 20:555-9. doi: 10.1158/1055-9965.EPI-10-0971.

17. Jakszyn PG, Allen NE, Lujan-Barroso L, Gonzalez CA, Key TJ, Fonseca-Nunes A, et al. Nitrosamines and heme iron and risk of prostate cancer in the European prospective investigation into cancer and nutrition. Cancer Epidemiol Biomarkers Prev. (2012) 21:547-51. doi: 10.1158/1055-9965.EPI-11-1181

18. Diallo A, Deschasaux M, Latino-Martel P, Hercberg S, Galan P, Fassier $\mathrm{P}$, et al. Red and processed meat intake and cancer risk:results from the prospective NutriNet-Santé cohort study. Int J Cancer. (2018) 142:230-7. doi: 10.1002/ijc.31046

19. Sesink AL, Termont DS, Kleibeuker JH, Van Der Meer R. Red meat and colon cancer, dietary haem, but not fat, has cytotoxic and hyperproliferative effects on rat colonic epithelium. Carcinogenesis. (2000) 21:1909-15. doi: 10.1093/carcin/21.10.1909

20. Bastide NM, Chenni F, Audebert M, Santarelli RL, Taché S, Naud N, et al. A central role for heme iron in colon carcinogenesis associated with red meat intake. Cancer Res. (2015) 75:870-9. doi: 10.1158/0008-5472.CAN-14-2554

21. Pierre F, Freeman A, Taché S, Van der Meer R, Corpet DE. Beef meat and blood sausage promote the formation of azoxymethane-induced mucindepleted foci and aberrant crypt foci in rat colons. J Nutr. (2004) 134:2711-6. doi: $10.1093 /$ jn/134.10.2711

22. Gamage SMK, Dissabandara L, Lam AK, Gopalan V. The role of heme iron molecules derived from red and processed meat in the pathogenesis of colorectal carcinoma. Crit Rev Oncol Hematol. (2018) 126:121-8. doi: 10.1016/j.critrevonc.2018.03.025

23. Massey RC, Key PE, Mallett AK, Rowland IR. An investigation of the endogenous formation of apparent total $\mathrm{N}$-nitroso compounds in conventional microflora and germ-free rats. Food Chem Toxicol. (1988) 26:595-600. doi: 10.1016/0278-6915(88)90230-X

24. Sasso A, Latella G. Role of heme iron in the association between red meat consumption and colorectal cancer. Nutr Cancer. (2018) 70:1173-83. doi: 10.1080/01635581.2018.1521441

25. IJssennagger N, Rijnierse A, de Wit N, Jonker-Termont D, Dekker J, Müller $\mathrm{M}$, et al. Dietary haem stimulates epithelial cell turnover by downregulating feedback inhibitors of proliferation in murine colon. Gut. (2012) 61:1041-9. doi: 10.1136/gutjnl-2011-300239

26. Liu H, Liu X, Zhang C, Zhu H, Xu Q, Bu Y, et al. Redox imbalance in the development of colorectal cancer. J Cancer. (2017) 8:1586-97. doi: $10.7150 /$ jca. 18735

27. Ijssennagger N, Rijnierse A, de Wit NJ, Boekschoten MV, Dekker J, Schonewille A, et al. Dietary heme induces acute oxidative stress, but delayed cytotoxicity and compensatory hyperproliferation in mouse colon. Carcinogenesis. (2013) 34:1628-35. doi: 10.1093/carcin/bgt084

28. Marnett LJ. Chemistry and biology of DNA damage by malondialdehyde. IARC Sci Publ. (1999) 150:17-27.

29. Corpet DE. Red meat and colon cancer:should we become vegetarians, or can we make meat safer? Meat Sci. (2011) 89:310-6. doi: 10.1016/j.meatsci.2011.04.009

30. Mirvish SS. Role of N-nitroso compounds (NOC) and N-nitrosation in etiology of gastric, esophageal, nasopharyngeal and bladder cancer and contribution to cancer of known exposures to NOC. Cancer Lett. (1995) 93:17-48. doi: 10.1016/0304-3835(95)03786-V

31. Bingham SA, Pignatelli B, Pollock JR, Ellul A, Malaveille C, Gross G, et al. Does increased endogenous formation of $\mathrm{N}$-nitroso compounds in the human colon explain the association between red meat and colon cancer? Carcinogenesis. (1996) 17:515-23. doi: 10.1093/carcin/17.3.515

32. Hughes R, Cross AJ, Pollock JR, Bingham S. Dose-dependent effect of dietary meat on endogenous colonic N-nitrosation. Carcinogenesis. (2001) 22:199-202. doi: 10.1093/carcin/22.1.199

33. Kruger C, Zhou Y. Red meat and colon cancer:a review of mechanistic evidence for heme in the context of risk assessment methodology. Food Chem Toxicol. (2018) 118:131-53. doi: 10.1016/j.fct.2018.04.048

34. IJssennagger N, Derrien M, van Doorn GM, Rijnierse A, van den Bogert B, Müller M, et al. Dietary heme alters microbiota and mucosa of mouse colon without functional changes in host-microbe cross-talk. PLoS ONE. (2012) 7:e49868. doi: 10.1371/journal.pone.0049868

35. Constante M, Fragoso G, Calvé A, Samba-Mondonga M, Santos MM. Dietary heme induces gut dysbiosis, aggravates colitis, and potentiates the development of adenomas in mice. Front Microbiol. (2017) 8:1809. doi: 10.3389/fmicb.2017.01809

36. Louis P, Hold GL, Flint HJ. The gut microbiota, bacterial metabolites and colorectal cancer. Nat Rev Microbiol. (2014) 12:661-72. doi: 10.1038/nrmicro3344

37. Nakatsu G, Li X, Zhou H, Sheng J, Wong SH, Wu WK, et al. Gut mucosal microbiome across stages of colorectal carcinogenesis. Nat Commun. (2015) 6:8727. doi: 10.1038/ncomms9727

38. Ijssennagger N, Belzer C, Hooiveld GJ, Dekker J, van Mil SW, Müller $\mathrm{M}$, et al. Gut microbiota facilitates dietary heme-induced epithelial hyperproliferation by opening the mucus barrier in colon. Proc Natl Acad Sci USA. (2015) 112:10038-43. doi: 10.1073/pnas.1507645112 
39. Chiabrando D, Mercurio S, Tolosano E. Heme and erythropoieis:more than a structural role. Haematologica. (2014) 99:973-83. doi: 10.3324/haematol.2013.091991

40. Malik Z, Lugaci H. Destruction of erythroleukaemic cells by photoactivation of endogenous porphyrins. Br J Cancer. (1987) 56:589-95. doi: 10.1038/bjc.1987.246

41. Kennedy JC, Pottier RH, Pross DC. Photodynamic therapy with endogenous protoporphyrin IX:basic principles and present clinical experience. $J$ Photochem Photobiol B. (1990) 6:143-8. doi: 10.1016/1011-1344(90)85083-9

42. Peng Q, Moan J, Warloe T, Nesland JM, Rimington C. Distribution and photosensitizing efficiency of porphyrins induced by application of exogenous 5 -aminolevulinic acid in mice bearing mammary carcinoma. Int J Cancer. (1992) 52:433-43. doi: 10.1002/ijc.2910520318

43. Yang X, Palasuberniam P, Kraus D, Chen B. Aminolevulinic acid-based tumor detection and therapy, molecular mechanisms and strategies for enhancement. Int J Mol Sci. (2015) 16:25865-80. doi: 10.3390/ijms161025865

44. Ye W, Zhang L. Heme deficiency causes apoptosis but does not increase ROS generation in HeLa cells. Biochem Biophys Res Commun. (2004) 319:1065-71. doi: 10.1016/j.bbrc.2004.05.089

45. Fukuda Y, Wang Y, Lian S, Lynch J, Nagai S, Fanshawe B, et al. Upregulated heme biosynthesis, an exploitable vulnerability in MYCN-driven leukemogenesis. JCI Insight. (2017) 2:92409. doi: 10.1172/jci.insight.92409

46. Hooda J, Cadinu D, Alam MM, Shah A, Cao TM, Sullivan LA, et al. Enhanced heme function and mitochondrial respiration promote the progression of lung cancer cells. PLoS ONE. (2013) 8:e63402. doi: 10.1371/journal.pone.0063402

47. Teng L, Nakada M, Zhao SG, Endo Y, Furuyama N, Nambu E, et al. Silencing of ferrochelatase enhances 5-aminolevulinic acid-based fluorescence and photodynamic therapy efficacy. Br J Cancer. (2011) 104:798-807. doi: 10.1038/bjc.2011.12

48. Wang J, Zhang J, Shi Y, Xu C, Zhang C, Wong YK, et al. Mechanistic investigation of the specific anticancer property of artemisinin and its combination with aminolevulinic acid for enhanced anticolorectal cancer activity. ACS Cent Sci. (2017) 3:743-50. doi: 10.1021/acscentsci.7b00156

49. Sohoni S, Ghosh P, Wang T, Kalainayakan SP, Vidal C, Dey S, et al. Elevated heme synthesis and uptake underpin intensified oxidative metabolism and tumorigenic functions in non-small cell lung cancer cells. Cancer Res. (2019) 79:2511-25. doi: 10.1158/0008-5472.CAN-18-2156

50. Peng C, Song Y, Chen W, Wang X, Liu X, Wang F, et al. FLVCR1 promotes the proliferation and tumorigenicity of synovial sarcoma through inhibiting apoptosis and autophagy. Int J Oncol. (2018) 55:1559-68. doi: $10.3892 /$ ijo.2018.4312

51. Alam MM, Lal S, FitzGerald KE, Zhang L. A holistic view of cancer bioenergetics, mitochondrial function and respiration play fundamental roles in the development and progression of diverse tumors. Clin Transl Med. (2016) 5:3. doi: 10.1186/s40169-016-0082-9

52. Sugiyama Y, Hagiya Y, Nakajima M, Ishizuka M, Tanaka T, Ogura S. The heme precursor 5-aminolevulinic acid disrupts the Warburg effect in tumor cells and induces caspase-dependent apoptosis. Oncol Rep. (2014) 31:1282-6. doi: 10.3892/or.2013.2945

53. Frezza C, Zheng L, Folger O, Rajagopalan KN, MacKenzie ED, Jerby L, et al. Haem oxygenase is synthetically lethal with the tumour suppressor fumarate hydratase. Nature. (2011) 477:225-8. doi: 10.1038/nature10363

54. Formentini L, Sánchez-Aragó M, Sánchez-Cenizo L, Cuezva JM. The mitochondrial ATPase inhibitory factor 1 triggers a ROS-mediated retrograde prosurvival and proliferative response. Mol Cell. (2012) 45:731-42. doi: 10.1016/j.molcel.2012.01.008

55. Shah DI, Takahashi-Makise N, Cooney JD, Li L, Schultz IJ, Pierce EL, et al. Mitochondrial Atpif1 regulates haem synthesis in developing erythroblasts. Nature. (2012) 491:608-12. doi: 10.1038/nature11536

56. Handschin C, Lin J, Rhee J, Peyer AK, Chin S, Wu PH, et al. Nutritional regulation of hepatic heme biosynthesis and porphyria through PGC-1alpha. Cell. (2005) 122:505-15. doi: 10.1016/j.cell.2005.06.040

57. Lynch JA, Fukuda Y, Krishnamurthy P, Wijaya J, Wang Y, Herras A, et al. Heme interaction with the pyruvate dehydrogenase complex:a novel strategy to promote hypoxic survival. FASEB J. (2019) 33:652.12
58. Chevrollier A, Loiseau D, Reynier P, Stepien G. Adenine nucleotide translocase 2 is a key mitochondrial protein in cancer metabolism. Biochim Biophys Acta. (2011) 1807:562-7. doi: 10.1016/j.bbabio.2010.10.008

59. Giraud S, Bonod-Bidaud C, Wesolowski-Louvel M, Stepien G. Expression of human ANT2 gene in highly proliferative cells, GRBOX, a new transcriptional element, is involved in the regulation of glycolytic ATP import into mitochondria. J Mol Biol. (1998) 281:409-18. doi: 10.1006/jmbi.1998.1955

60. Halestrap AP, Brenner C. The adenine nucleotide translocase, a central component of the mitochondrial permeability transition pore and key player in cell death. Curr Med Chem. (2003) 10:1507-25. doi: 10.2174/0929867033457278

61. Bauer MK, Schubert A, Rocks O, Grimm S. Adenine nucleotide translocase1, a component of the permeability transition pore, can dominantly induce apoptosis. J Cell Biol. (1999) 147:1493-502. doi: 10.1083/jcb.147.7.1493

62. Zamora M, Granell M, Mampel T, Viñas O. Adenine nucleotide translocase 3 (ANT3) overexpression induces apoptosis in cultured cells. FEBS Lett. (2004) 563:155-60. doi: 10.1016/S0014-5793(04)00293-5

63. Azuma M, Kabe Y, Kuramori C, Kondo M, Yamaguchi Y, Handa H. Adenine nucleotide translocator transports haem precursors into mitochondria. PLoS ONE. (2008) 3:e3070. doi: 10.1371/journal.pone.0003070

64. Sabová L, Zeman I, Supek F, Kolarov J. Transcriptional control of AAC3 gene encoding mitochondrial ADP/ATP translocator in saccharomyces cerevisiae by oxygen, heme and ROX1 factor. Eur J Biochem. (1993) 213:547-53. doi: 10.1111/j.1432-1033.1993.tb17793.x

65. Chevrollier A, Loiseau D, Gautier F, Malthièry Y, Stepien G. ANT2 expression under hypoxic conditions produces opposite cell-cycle behavior in 143B and HepG2 cancer cells. Mol Carcinog. (2005) 42:1-8. doi: 10.1002/mc. 20059

66. Brenner C, Subramaniam K, Pertuiset C, Pervaiz S. Adenine nucleotide translocase family:four isoforms for apoptosis modulation in cancer. Oncogene. (2011) 30:883-95. doi: 10.1038/onc.2010.501

67. Baik SH, Lee J, Lee YS, Jang JY, Kim CW. ANT2 shRNA downregulates miR-19a and miR-96 through the PI3K/Akt pathway and suppresses tumor growth in hepatocellular carcinoma cells. Exp Mol Med. (2016) 48:e222. doi: $10.1038 / \mathrm{emm} .2015 .126$

68. Wen S, Zhu D, Huang P. Targeting cancer cell mitochondria as a therapeutic approach. Future Med Chem. (2013) 5:53-67. doi: 10.4155/fmc.12.190

69. Korolnek T, Hamza I. Like iron in the blood of the people:the requirement for heme trafficking in iron metabolism. Front Pharmacol. (2014) 5:126. doi: 10.3389/fphar.2014.00126

70. Flonta SE, Arena S, Pisacane A, Michieli P, Bardelli A. Expression and functional regulation of myoglobin in epithelial cancers. Am J Pathol. (2009) 175:201-6. doi: 10.2353/ajpath.2009.081124

71. Hornyák L, Dobos N, Koncz G, Karányi Z, Páll D, Szabó Z, et al. The role of indoleamine-2,3-dioxygenase in cancer development, diagnostics, and therapy. Front Immunol. (2018) 9:151. doi: 10.3389/fimmu.2018.00151

72. Yu CP, Song YL, Zhu ZM, Huang B, Xiao YQ, Luo DY. Targeting TDO in cancer immunotherapy. Med Oncol. (2017) 34:73. doi: 10.1007/s12032-017-0933-2

73. Yan D, Lin YW, Tan X. Heme-containing enzymes and inhibitors for tryptophan metabolism. Metallomics. (2017) 9:1230-40. doi: 10.1039/C7MT00105C

74. Rohlena J, Dong LF, Neuzil J. Targeting the mitochondrial electron transport chain complexes for the induction of apoptosis and cancer treatment. Curr Pharm Biotechnol. (2013) 14:377-89. doi: 10.2174/13892010113140 30011

75. Ashton TM, McKenna WG, Kunz-Schughart LA, Higgins GS. Oxidative phosphorylation as an emerging target in cancer therapy. Clin Cancer Res. (2018) 24:2482-90. doi: 10.1158/1078-0432.CCR-17-3070

76. Rodriguez-Antona C, Ingelman-Sundberg M. Cytochrome P450 pharmacogenetics and cancer. Oncogene. (2006) 25:1679-91. doi: 10.1038/sj.onc.1209377

77. Mittal B, Tulsyan S, Kumar S, Mittal RD, Agarwal G. Cytochrome P450 in cancer susceptibility and treatment. Adv Clin Chem. (2015) 71:77-139. doi: 10.1016/bs.acc.2015.06.003 
78. Hashemi Goradel N, Najafi M, Salehi E, Farhood B, Mortezaee K. Cyclooxygenase-2 in cancer:a review. J Cell Physiol. (2019). 234:5683-99. doi: $10.1002 /$ jcp. 27411

79. Pannunzio A, Coluccia M. Cyclooxygenase-1 (COX-1) and COX-1 inhibitors in cancer, a review of oncology and medicinal chemistry literature. Pharmaceuticals. (2018) 11:E101. doi: 10.3390/ph11040101

80. Destefanis F, Fiorito V, Altruda F, Tolosano E. Investigating the connection between endogenous heme accumulation and COX2 activity in cancer cells. Front Oncol. (2019) 9:162. doi: 10.3389/fonc.2019.00162

81. Yin L, Wu N, Curtin JC, Qatanani M, Szwergold NR, Reid RA, et al. Reverbalpha, a heme sensor that coordinates metabolic and circadian pathways. Science. (2007) 318:1786-9. doi: 10.1126/science.1150179

82. Dioum EM, Rutter J, Tuckerman JR, Gonzalez G, Gilles-Gonzalez MA, McKnight SL. NPAS2:a gas-responsive transcription factor. Science. (2002) 298:2385-7. doi: 10.1126/science.1078456

83. Kaasik K, Lee CC. Reciprocal regulation of haem biosynthesis and the circadian clock in mammals. Nature. (2004) 430:467-71. doi: $10.1038 /$ nature 02724

84. Kitanishi K, Igarashi J, Hayasaka K, Hikage N, Saiful I, Yamauchi S, et al. Heme-binding characteristics of the isolated PAS-A domain of mouse Per2, a transcriptional regulatory factor associated with circadian rhythms. Biochemistry. (2008) 47:6157-68. doi: 10.1021/bi7023892

85. Sulli G, Lam MT Y, Panda S. Interplay between circadian clock and cancer:new frontiers for cancer treatment. Trends Cancer. (2019) 5:475-94. doi: 10.1016/j.trecan.2019.07.002

86. Kastenhuber ER, Lowe SW. Putting p53 in context. Cell. (2017) 170:1062-78. doi: 10.1016/j.cell.2017.08.028

87. Shen J, Sheng X, Chang Z, Wu Q, Wang S, Xuan Z, et al. Iron metabolism regulates $\mathrm{p} 53$ signaling through direct heme-p53 interaction and modulation of p53 localization, stability, and function. Cell Rep. (2014) 7:180-93. doi: 10.1016/j.celrep.2014.02.042

88. Torti SV, Torti FM. Iron and cancer, more ore to be mined. Nat Rev Cancer. (2013) 13:342-55. doi: 10.1038/nrc3495

89. Russo V, Roperto F, Taulescu M, De Falco F, Urraro C, Corrado F, et al. Expression of the feline leukemia virus subgroup $\mathrm{C}$ receptors in normal and neoplastic urothelium of the urinary bladder of cattle associated with bovine papillomavirus infection. Vet Microbiol. (2019) 229:147-52. doi: 10.1016/j.vetmic.2018.12.024

90. Kazuhiro H, Hirofumi M, Masato T, Osamu S, Mariko H, Tsuyoshi K, et al. Cancer cells uptake porphyrins via heme carrier protein 1. J Porphyrins Phthal. (2013) 17:36-43. doi: 10.1142/S1088424612501192

91. O'Callaghan KM, Ayllon V, O'Keeffe J, Wang Y, Cox OT, Loughran $\mathrm{G}$, et al. Heme-binding protein HRG-1 is induced by insulin-like growth factor I and associates with the vacuolar H+-ATPase to control endosomal pH and receptor trafficking. J Biol Chem. (2010) 285:381-91. doi: 10.1074/jbc.M109.063248

92. Fogarty FM, O'Keeffe J, Zhadanov A, Papkovsky D, Ayllon V, O'Connor R. HRG-1 enhances cancer cell invasive potential and couples glucose metabolism to cytosolic/extracellular $\mathrm{pH}$ gradient regulation by the vacuolar-H(+) ATPase. Oncogene. (2014) 33:4653-63. doi: 10.1038/onc.20 13.403

93. Shen Y, Li X, Zhao B, Xue Y, Wang S, Chen X, et al. Iron metabolism gene expression and prognostic features of hepatocellular carcinoma. J Cell Biochem. (2018) 119:9178-9204. doi: 10.1002/jcb.27184

94. Chiabrando D, Castori M, di Rocco M, Ungelenk M, Gießelmann S, Di Capua M, et al. Mutations in the heme exporter FLVCR1 cause sensory neurodegeneration with loss of pain perception. PLoS Genet. (2016) 12:e1006461. doi: 10.1371/journal.pgen.1006461

95. Palasuberniam P, Yang X, Kraus D, Jones P, Myers KA, Chen B. ABCG2 transporter inhibitor restores the sensitivity of triple negative breast cancer cells to aminolevulinic acid-mediated photodynamic therapy. Sci Rep. (2015) 5:13298. doi: 10.1038/srep 13298

96. Westover D, Li F. New trends for overcoming ABCG2/BCRP-mediated resistance to cancer therapies. J Exp Clin Cancer Res. (2015) 34:159. doi: 10.1186/s13046-015-0275-x

97. Kim JH, Park JM, Roh YJ, Kim IW, Hasan T, Choi MG. Enhanced efficacy of photodynamic therapy by inhibiting ABCG2 in colon cancers. BMC Cancer. (2015) 15:504. doi: 10.1186/s12885-015-1514-4
98. Chiabrando D, Marro S, Mercurio S, Giorgi C, Petrillo S, Vinchi F, et al. The mitochondrial heme exporter FLVCR1b mediates erythroid differentiation. $J$ Clin Invest. (2012) 122:4569-79. doi: 10.1172/JCI62422

99. Was H, Dulak J, Jozkowicz A. Heme oxygenase-1 in tumor biology and therapy. Curr Drug Targets. (2010) 11:1551-70. doi: 10.2174/1389450111009011551

100. Nitti M, Piras S, Marinari UM, Moretta L, Pronzato MA, Furfaro AL. HO1 induction in cancer progression:a matter of cell adaptation. Antioxidants. (2017) 6:E29. doi: 10.3390/antiox6020029

101. Loboda A, Jozkowicz A, Dulak J. HO-1/CO system in tumor growth, angiogenesis and metabolism-targeting $\mathrm{HO}-1$ as an anti-tumor therapy. Vascul Pharmacol. (2015) 74:11-22. doi: 10.1016/j.vph.2015.09.004

102. Lin Q, Weis S, Yang G, Weng YH, Helston R, Rish K, et al. Heme oxygenase-1 protein localizes to the nucleus and activates transcription factors important in oxidative stress. J Biol Chem. (2007) 282:20621-33. doi: 10.1074/jbc.M607954200

103. Sacca P, Meiss R, Casas G, Mazza O, Calvo JC, Navone N, et al. Nuclear translocation of haeme oxygenase-1 is associated to prostate cancer. $\mathrm{Br} J$ Cancer. (2007) 97:1683-9. doi: 10.1038/sj.bjc.6604081

104. Laplagne C, Domagala M, Le Naour A, Quemerais C, Hamel D, Fournié JJ, et al. Latest advances in targeting the tumor microenvironment for tumor suppression. Int J Mol Sci. (2019) 20:4719. doi: 10.3390/ijms20194719

105. Bussard KM, Mutkus L, Stumpf K, Gomez-Manzano C, Marini FC. Tumorassociated stromal cells as key contributors to the tumor microenvironment. Breast Cancer Res. (2016) 18:84. doi: 10.1186/s13058-016-0740-2

106. Gordon S, Taylor PR. Monocyte and macrophage heterogeneity. Nat Rev Immunol. (2005) 5:953-64. doi: 10.1038/nri1733

107. Pollard JW. Tumour-educated macrophages promote tumour progression and metastasis. Nat Rev Cancer. (2004) 4:71-8. doi: 10.1038/nrc1256

108. Mantovani A, Sozzani S, Locati M, Allavena P, Sica A. Macrophage polarization:tumor-associated macrophages as a paradigm for polarized M2 mononuclear phagocytes. Trends Immunol. (2002) 23:549-55. doi: 10.1016/S1471-4906(02)02302-5

109. Reichel D, Tripathi M, Perez JM. Biological effects of nanoparticles on macrophage polarization in the tumor microenvironment. Nanotheranostics. (2019) 3:66-88. doi: 10.7150/ntno.30052

110. Hashizume H, Baluk P, Morikawa S, McLean JW, Thurston G, Roberge S, et al. Openings between defective endothelial cells explain tumor vessel leakiness. Am J Pathol. (2000) 156:1363-80. doi: 10.1016/S0002-9440(10)65006-7

111. Costa da Silva M, Breckwoldt MO, Vinchi F, Correia MP, Stojanovic A, Thielmann CM, et al. Iron induces anti-tumor activity in tumor-associated macrophages. Front Immunol. (2017) 8:1479. doi: 10.3389/fimmu.2017.01479

112. Vinchi F, Costa da Silva M, Ingoglia G, Petrillo S, Brinkman N, Zuercher A, et al. Hemopexin therapy reverts heme-induced proinflammatory phenotypic switching of macrophages in a mouse model of sickle cell disease. Blood. (2016) 127:473-86. doi: 10.1182/blood-2015-08-663245

113. Sindrilaru A, Peters T, Wieschalka S, Baican C, Baican A, Peter H, et al. An unrestrained proinflammatory M1 macrophage population induced by iron impairs wound healing in humans and mice. J Clin Invest. (2011) 121:985-97. doi: 10.1172/JCI44490

114. Kroner A, Greenhalgh AD, Zarruk JG, Passos Dos Santos R, Gaestel M, David S. TNF and increased intracellular iron alter macrophage polarization to a detrimental M1 phenotype in the injured spinal cord. Neuron. (2014) 83:1098-116. doi: 10.1016/j.neuron.2014.07.027

115. Wegiel B, Gallo D, Csizmadia E, Harris C, Belcher J, Vercellotti GM, et al. Carbon monoxide expedites metabolic exhaustion to inhibit tumor growth. Cancer Res. (2013) 73:7009-21. doi: 10.1158/0008-5472.CAN-13-1075

116. Nemeth Z, Csizmadia E, Vikstrom L, Li M, Bisht K, Feizi A, et al. Alterations of tumor microenvironment by carbon monoxide impedes lung cancer growth. Oncotarget. (2016) 7:23919-32. doi: 10.18632/oncotarget.8081

117. Hida K, Maishi N, Torii C, Hida Y. Tumor angiogenesis-characteristics of tumor endothelial cells. Int J Clin Oncol. (2016) 21:206-12. doi: 10.1007/s10147-016-0957-1

118. Zecchin A, Borgers G, Carmeliet P. Endothelial cells and cancer cells, metabolic partners in crime? Curr Opin Hematol. (2015) 22:234-42. doi: $10.1097 / \mathrm{MOH} .0000000000000138$ 
119. De Bock K, Georgiadou M, Carmeliet P. Role of endothelial cell metabolism in vessel sprouting. Cell Metab. (2013) 18:634-47. doi: 10.1016/j.cmet.2013.08.001

120. Cantelmo AR, Brajic A, Carmeliet P. Endothelial metabolism driving angiogenesis: emerging concepts and principles. Cancer J. (2015) 21:244-9. doi: 10.1097/PPO.0000000000000133

121. Choi H, Moon A. Crosstalk between cancer cells and endothelial cells: implications for tumor progression and intervention. Arch Pharm Res. (2018) 41:711-24. doi: 10.1007/s12272-018-1051-1

122. Maishi N, Hida K. Tumor endothelial cells accelerate tumor metastasis. Cancer Sci. (2017) 108:1921-6. doi: 10.1111/cas.13336

123. Petrillo S, Chiabrando D, Genova T, Fiorito V, Ingoglia G, Vinchi F, et al. Heme accumulation in endothelial cells impairs angiogenesis by triggering paraptosis. Cell Death Differ. (2018) 25:573-88. doi: 10.1038/s41418-017-0001-7

124. Vandekeere S, Dubois C, Kalucka J, Sullivan MR, García-Caballero M, Goveia J, et al. Serine synthesis via $\mathrm{PHGDH}$ is essential for heme production in endothelial cells. Cell Metab. (2018) 28:573-87.e13. doi: 10.1016/j.cmet.2018.06.009

125. Bordeleau F, Mason BN, Lollis EM, Mazzola M, Zanotelli MR, Somasegar S, et al. Matrix stiffening promotes a tumor vasculature phenotype. Proc Natl Acad Sci USA. (2017) 114:492-7. doi: 10.1073/pnas.1613855114

126. Wang W, Lollis EM, Bordeleau F, Reinhart-King CA. Matrix stiffness regulates vascular integrity through focal adhesion kinase activity. FASEB J. (2019) 33:1199-208. doi: 10.1096/fj.201800841R

127. DeNichilo MO, Panagopoulos V, Rayner TE, Borowicz RA, Greenwood JE, Evdokiou Al. Peroxidase enzymes regulate collagen extracellular matrix biosynthesis. Am J Pathol. (2015) 185:1372-84. doi: 10.1016/j.ajpath.2015.01.013

128. Panagopoulos V, Leach DA, Zinonos I, Ponomarev V, Licari G, Liapis $\mathrm{V}$, et al. Inflammatory peroxidases promote breast cancer progression in mice via regulation of the tumour microenvironment. Int J Oncol. (2017) 50:1191-200. doi: 10.3892/ijo.2017.3883

129. Jobling P, Pundavela J, Oliveira SM, Roselli S, Walker MM, Hondermarck H. Nerve-cancer cell cross-talk: a novel promoter of tumor progression. Cancer Res. (2015) 75:1777-81. doi: 10.1158/0008-5472.CAN-14-3180

130. Griffin N, Faulkner S, Jobling P, Hondermarck H. Targeting neurotrophin signaling in cancer: the renaissance. Pharmacol Res. (2018) 135:12-7. doi: 10.1016/j.phrs.2018.07.019

131. Kuol N, Stojanovska L, Apostolopoulos V, Nurgali K. Crosstalk between cancer and the neuro-immune system. J Neuroimmunol. (2018) 315:15-23. doi: 10.1016/j.jneuroim.2017.12.016

132. Kuol N, Stojanovska L, Apostolopoulos V, Nurgali K. Role of the nervous system in cancer metastasis. J Exp Clin Cancer Res. (2018) 37:5. doi: 10.1186/s13046-018-0674-x

133. Renz BW, Takahashi R, Tanaka T, Macchini M, Hayakawa Y, Dantes Z, et al. $\beta 2$ adrenergic-neurotrophin feedforward loop promotes pancreatic cancer. Cancer Cell. (2018) 33:75-90.e7. doi: 10.1016/j.ccell.2017.11.007

134. Hayakawa Y, Sakitani K, Konishi M, Asfaha S, Niikura R, Tomita $\mathrm{H}$, et al. Nerve growth factor promotes gastric tumorigenesis through aberrant cholinergic signaling. Cancer Cell. (2017) 31:21-34. doi: 10.1016/j.ccell.2016.11.005

135. Zahalka AH, Arnal-Estapé A, Maryanovich M, Nakahara F, Cruz CD, Finley LW S, et al. Adrenergic nerves activate an angio-metabolic switch in prostate cancer. Science. (2017) 358:321-6. doi: 10.1126/science.aah5072

136. Kuol N, Stojanovska L, Apostolopoulos V, Nurgali K. Role of the nervous system in tumor angiogenesis. Cancer Microenviron. (2018) 11:1-11. doi: $10.1007 /$ s12307-018-0207-3

137. Gozzelino R. The pathophysiology of heme in the brain. Curr Alzheimer Res. (2016) 13:174-84. doi: 10.2174/1567205012666150921103304

138. Chiabrando D, Fiorito V, Petrillo S, Tolosano E. Unraveling the role of heme in neurodegeneration. Front Neurosci. (2018) 12:712. doi: $10.3389 /$ fnins.2018.00712

139. Saloman JL, Albers KM, Li D, Hartman DJ, Crawford HC, Muha EA, et al. Ablation of sensory neurons in a genetic model of pancreatic ductal adenocarcinoma slows initiation and progression of cancer. Proc Natl Acad Sci USA. (2016) 113:3078-83. doi: 10.1073/pnas.1512603113
140. Demir IE, Friess H, Ceyhan GO. Neural plasticity in pancreatitis and pancreatic cancer. Nat Rev Gastroenterol Hepatol. (2015) 12:649-59. doi: $10.1038 /$ nrgastro.2015.166

141. Stopczynski RE, Normolle DP, Hartman DJ, Ying H, DeBerry JJ, Bielefeldt K, et al. Neuroplastic changes occur early in the development of pancreatic ductal adenocarcinoma. Cancer Res. (2014) 74:1718-27. doi: 10.1158/0008-5472.CAN-13-2050

142. Tracy JA, Dyck PJ. Porphyria and its neurologic manifestations. Handb Clin Neurol. (2014) 120:839-49. doi: 10.1016/B978-0-7020-4087-0.00056-5

143. Lin CS, Lee MJ, Park SB, Kiernan MC. Purple pigments: the pathophysiology of acute porphyric neuropathy. Clin Neurophysiol. (2011) 122:2336-44. doi: 10.1016/j.clinph.2011.07.036

144. Piguet F, de Montigny C, Vaucamps N, Reutenauer L, Eisenmann A, Puccio H. Rapid and complete reversal of sensory ataxia by gene therapy in a novel model of friedreich ataxia. Mol Ther. (2018) 26:1940-52. doi: 10.1016/j.ymthe.2018.05.006

145. Rajadhyaksha AM, Elemento O, Puffenberger EG, Schierberl KC, Xiang JZ, Putorti ML, et al. Mutations in FLVCR1 cause posterior column ataxia and retinitis pigmentosa. Am J Hum Genet. (2010) 87:643-54. doi: 10.1016/j.ajhg.2010.10.013

146. Smith AG, Raven EL, Chernova T. The regulatory role of heme in neurons. Metallomics. (2011) 3:955-62. doi: 10.1039/c1mt00085c

147. V Subramaniam A, Salem Yehya AH, Oon CE. Molecular basis of cancer pain management: an updated review. Medicina. (2019) 55:E584. doi: 10.3390/medicina55090584

148. Mantyh PW. Cancer pain and its impact on diagnosis, survival and quality of life. Nat Rev Neurosci. (2006) 7:797-809. doi: 10.1038/nrn1914

149. Bertino F, Firestone K, Bellacchio E, Jackson KE, Asamoah A, Hersh J, et al. Heme and sensory neuropathy: insights from novel mutations in the heme exporter feline leukemia virus subgroup C Receptor 1. Pain. (2019) 160:2766-75. doi: 10.1097/j.pain.0000000000001675.

150. Castori M, Morlino S, Ungelenk M, Pareyson D, Salsano E, Grammatico $\mathrm{P}$, et al. Posterior column ataxia with retinitis pigmentosa coexisting with sensory-autonomic neuropathy and leukemia due to the homozygous p.Pro221Ser FLVCR1 mutation. Am J Med Genet B Neuropsychiatr Genet. (2017) 174:732-9. doi: 10.1002/ajmg.b.32570

151. Fan W, Huang F, Wu Z, Zhu X, Li D, He H. Carbon monoxide: a gas that modulates nociception. J Neurosci Res. (2011) 89:802-7. doi: $10.1002 /$ jnr.22613

152. Peng Y, Croce CM. The role of MicroRNAs in human cancer. Signal Transduct Target Ther. (2016) 1:15004. doi: 10.1038/sigtrans.2015.4

153. Faller M, Matsunaga M, Yin S, Loo JA, Guo F. Heme is involved in microRNA processing. Nat Struct Mol Biol. (2007) 14:23-9. doi: 10.1038/nsmb1182

154. Barr I, Smith AT, Chen Y, Senturia R, Burstyn JN, Guo F. Ferric, not ferrous, heme activates RNA-binding protein DGCR8 for primary microRNA processing. Proc Natl Acad Sci USA. (2012) 109:1919-24. doi: 10.1073/pnas.1114514109

155. Nguyen TA, Park J, Dang TL, Choi YG, Kim VN. Microprocessor depends on hemin to recognize the apical loop of primary microRNA. Nucleic Acids Res. (2018) 46:5726-36. doi: 10.1093/nar/gky248

156. Partin AC, Ngo TD, Herrell E, Jeong BC, Hon G, Nam Y. Heme enables proper positioning of drosha and DGCR8 on primary microRNAs. Nat Commun. (2017) 8:1737. doi: 10.1038/s41467-017-01713-y

157. Weitz SH, Gong M, Barr I, Weiss S, Guo F. Processing of microRNA primary transcripts requires heme in mammalian cells. Proc Natl Acad Sci USA. (2014) 111:1861-6. doi: 10.1073/pnas.1309915111

158. Fang CY, Chen PY, Ho DC, Tsai LL, Hsieh PL, Lu MY, et al. miR-145 mediates the anti-cancer stemness effect of photodynamic therapy with 5aminolevulinic acid (ALA) in oral cancer cells. J Formos Med Assoc. (2018) 117:738-42. doi: 10.1016/j.jfma.2018.05.018

159. Jin $Y$, Guan Z, Wang X, Wang Z, Zeng R, Xu L, et al. ALA-PDT promotes HPV-positive cervical cancer cells apoptosis and DCs maturation via miR-34a regulated HMGB1 exosomes secretion. Photodiagnosis Photodyn Ther. (2018) 24:27-35. doi: 10.1016/j.pdpdt.2018. 08.006

160. Guo Q, Dong B, Nan F, Guan D, Zhang Y. 5-Aminolevulinic acid photodynamic therapy in human cervical cancer via the activation of 
microRNA-143 and suppression of the Bcl-2/Bax signaling pathway. Mol Med Rep. (2016) 14:544-50. doi: 10.3892/mmr.2016.5248

161. Hu Z, Fan H, Lv G, Zhou Q, Yang B, Zheng J, et al. 5-Aminolevulinic acid-mediated sonodynamic therapy induces anti-tumor effects in malignant melanoma via p53-miR-34a-Sirt1 axis. J Dermatol Sci. (2015) 79:155-62. doi: 10.1016/j.jdermsci.2015.04.010

162. Dawson MA, Kouzarides T. Cancer epigenetics: from mechanism to therapy. Cell. (2012) 150:12-27. doi: 10.1016/j.cell.2012.06.013

163. Sapienza C, Issa JP. Diet, nutrition, cancer epigenetics. Annu Rev Nutr. (2016) 36:665-81. doi: 10.1146/annurev-nutr-121415-112634

164. Lal S, Comer JM, Konduri PC, Shah A, Wang T, Lewis A, et al. Heme promotes transcriptional and demethylase activities of Gis1, a member of the histone demethylase JMJD2/KDM4 family. Nucleic Acids Res. (2018) 46:215-28. doi: 10.1093/nar/gkx1051

165. Etchegaray JP, Mostoslavsky R. Interplay between metabolism and epigenetics, a nuclear adaptation to environmental changes. Mol Cell. (2016) 62:695-711. doi: 10.1016/j.molcel.2016.05.029

166. Fiorito V, Chiabrando D, Tolosano E. Mitochondrial targeting in neurodegeneration: a heme perspective. Pharmaceuticals. (2018) 11: E87. doi: $10.3390 / \mathrm{ph} 11030087$

167. Lin KH, Xie A, Rutter JC, Ahn YR, Lloyd-Cowden JM, Nichols AG, et al. Systematic dissection of the metabolic-apoptotic interface in AML reveals heme biosynthesis to be a regulator of drug sensitivity. Cell Metab. (2019) 29:1217-31.e7. doi: 10.1016/j.cmet.2019.01.011

168. Lee D, Kim IY, Saha S, Choi KS. Paraptosis in the anti-cancer arsenal of natural products. Pharmacol Ther. (2016) 162:120-33. doi: 10.1016/j.pharmthera.2016.01.003
169. Vallelian F, Deuel JW, Opitz L, Schaer CA, Puglia M, Lönn M, et al. Proteasome inhibition and oxidative reactions disrupt cellular homeostasis during heme stress. Cell Death Differ. (2015) 22:597-611. doi: $10.1038 /$ cdd.2014.154

170. Manasanch EE, Orlowski RZ. Proteasome inhibitors in cancer therapy. Nat Rev Clin Oncol. (2017) 14:417-33. doi: 10.1038/nrclinonc.2016.206

171. Nokes B, Apel M, Jones C, Brown G, Lang JE. Aminolevulinic acid (ALA): photodynamic detection and potential therapeutic applications. J Surg Res. (2013) 181:262-71. doi: 10.1016/j.jss.2013. 02.002

172. Bordini J, Galvan S, Ponzoni M, Bertilaccio MT, Chesi M, Bergsagel $\mathrm{PL}$, et al. Induction of iron excess restricts malignant plasma cells expansion and potentiates bortezomib effect in models of multiple myeloma. Leukemia. (2017) 31:967-70. doi: 10.1038/leu.20 16.346

Conflict of Interest: The authors declare that the research was conducted in the absence of any commercial or financial relationships that could be construed as a potential conflict of interest.

Copyright $\odot 2020$ Fiorito, Chiabrando, Petrillo, Bertino and Tolosano. This is an open-access article distributed under the terms of the Creative Commons Attribution License (CC BY). The use, distribution or reproduction in other forums is permitted, provided the original author(s) and the copyright owner(s) are credited and that the original publication in this journal is cited, in accordance with accepted academic practice. No use, distribution or reproduction is permitted which does not comply with these terms. 